\title{
Gracia desbordante y teología práctica, según Edith Stein, Die Seelenburg
}

\author{
Anneliese Meis \\ FACULTAD DE TEOLOGÍA \\ PONTIFICIA UNIVERSIDAD CATÓLICA DE CHILE
}

Si bien el estudio de Edith Stein Die Seelenburg es un comentario a Las Moradas de Teresa de Ávila ${ }^{1}$ y como tal evoca muchos aspectos tratados en profundidad desde una perspectiva lingüística y teológica espiritual ${ }^{2}$, el aporte propio de la santa filósofa, mística e hija espiritual de la Madre Teresa, resalta en aquellos acentos que ella, más allá de las referencias a la obra teresiana, ofrece a partir de un enfoque fenomenológico. $\mathrm{He}$ analizado e interpretado estos acentos desde una perspectiva teológica sistemática para verificar la relevancia teológica de estos acentos para el proceso formativo de educar al ser humano hoy. Siendo Edith Stein, pues, además de carmelita una pedagoga destacada ${ }^{3}$, que no solo aporta con su propia experiencia concreta, sino también ha escrito estudios relevantes sobre las múltiples implicaciones que conlleva la visión antropológica teológica del ser humano en el mundo comprendido como trascendiendo hacia un único fin último, la felicidad, que le procura la visión de Dios y como tal responde a los deseos más íntimos de su corazón ${ }^{4}$. Expondré a continuación los resultados obtenidos de mi trabajo en

1 E. Stein, Die Seelenburg, en Endliches und ewiges Sein. Versuch eines Aufstiegs zum Sinn des Seins. Anhang: Martin Heideggers Existenzphilosophie. Die Seelenburg, Eingeführt und bearbeitet von Andres Uwe Müller (ESG 11/12), Freiburg-BaselWien, 2006, 501-525; por razones prácticas se cita según el texto traducido, $E l$ Castillo Interior, OC V, 80-106.

2 VRI, Proyecto Especial Interdiciplinar 2011.

3 E. DE RUS, «Eduquer avec Edith Stein: un service de 1' humanité», Teresianum 59 (2008), 241-266.

4 E. Stein, Obras Completas IV (Burgos 2005): El valor especifico de la mujer en su significado para la vida del pueblo, Obras completas IV, 71-87; El ethos de las 
El Castillo Interior, en la medida en que logré verificar la hipótesis «Educar para la gracia desbordante conduce a la plena autorrealización de los participantes del proceso formativo, a partir de los deseos más íntimos de sus corazones». Confrontaré estos resultados a modo de conclusión, con las respuestas obtenidas en dos cursos de Antropología Teológica de la Facultad de Teología, dictado durante el presente año en dos niveles distintos, es decir, del currículum pastoral y del teológico.

En efecto, los pasos metodológicos concretos, analíticos y sintéticos a la vez, del método aplicado a Die Seelenburg de Edith Stein se configuran a modo de una "lectura orgánica del texto» y como tales se orientan por la hipótesis señalada. Más que abordar las implicaciones prácticas, quisiera insistir en los fundamentos teológicos que emergen del texto steineano y que podrá constatarse a lo largo de todas las obras de la autora en cuanto propio de su forma mentis. Dichas implicaciones se plasman, de hecho, a través de los cuatro ejes transversales, que conlleva la hipótesis del trabajo realizado.

\section{El educar EN CUANTO PROCESo Formativo y SUS ElEMENTOS CONSTITUTIVOS}

Si educar, según su etimología, significa, «sacar fuera» aquello que está presente en el hombre y conducirlo hacia aquella plenitud significativa a que debe aspirar -resumen- estamos refiriéndonos a un proceso que se configura en torno a un "con» común, que involucra tanto al educando como al educador y nos preguntamos: ¿cuáles son los elementos teológicos que constituyen este proceso según Die Seelenburg de Edith Stein?

a. La indagación teórica de la constitución del ser humano

Insiste la autora, en primer lugar, en la necesidad de que «en nuestro contexto tenemos que afrontar el intento puramente teórico de indagar en la constitución graduada de los seres las notas específicas del ser hu-

profesiones femeninas, Obras completas IV, 159-176; Fundamentos de la formación de la mujer, Obras completas IV, 195-213; La misión de la mujer, Obras completas IV, 245-254; Vocación del hombre y de la mujer según el orden de la naturaleza y de la gracia, Obras completas IV, 271-296; Vida cristiana de la mujer, Obras completas IV, 311-351; Problemas de la formación de la mujer, Obras completas IV, 451-551; Estructura de la persona humana, Obras Completas IV, 555-749; ¿Qué es el hombre? La antropología de la doctrina católica de la fe, Obras completas IV, 753-986. 
mano, en el cual entra la definición del alma como centro de todo ese edificio que llamamos "hombre" " ${ }^{5}$; es decir, todo educar requiere "contextualizarse» y como tal ser «indagado» de modo «teórico» en cuanto a las "notas específicas del ser humano». Llama la atención que dichas notas, o elementos constituyentes del proceso formativo, se articulan al interior de una "constitución graduada de los seres», esto es, en relación con «todo ese edificio que llamamos hombre». El hombre entonces es concebido al interior de la "graduación de seres" que Edith Stein comprende a partir de su centro, el alma. Llegar a este centro y salir de él será, sin duda, la dinámica básica del proceso formativo del educar en nuestro contexto tendiente a la dispersión.

De hecho, enfrentar la dispersión, causada por «ansias y confusiones» y «la falta de un buen guía espiritual», resalta como el objetivo primordial del educar. Como tal este objetivo se interrelaciona, más allá del propio esfuerzo - «ella misma había tenido que combatir»- con otro -el guía espiritual-, pero se encuentra basado en las "gracias místicas», que según Edith Stein, recordando las palabras de Teresa, cabe «librarlas de las ansias y confusiones ${ }^{6}$. La autora enfatiza así la importancia de una liberación de fuerzas negativas y la necesidad de la ayuda de «otro», «un guía espiritual»-es decir, una persona experimentada- que posibilite aquello que no es posible por propia cuenta. De ahí que resalta la relación entre educando y educador como dimensión fundamental del proceso formativo, relación, por cierto, anticipada por "gracias místicas", es decir, dones, que posibilitan la experiencia del misterio, lo cual significa que teológicamente visto la relación del educando con el educador, en definitiva, se abre al misterio trascendente, en el cual cabe reconocer la condición de posibilidad del proceso educativo desde la perspectiva teológica. Finalmente, vale recordar el hecho de que asoma, junto con el fenómeno de la relación, una configuración espacial-no-espacial -el hábitat concreto-, pues el ser humano es designado como un «edificio», en el cual acontece el proceso formativo, condicionado a las diver-

5 CI 80. SB 39: «In unserem Zusammenhang ist die rein theoretische Aufgabe zu lösen, im Stufenbau des Seienden die Eigentümlichkeit des menschlichen Seins heraus zuarbeiten, und dazu gehört die Kennzeichnung der Seele als der Mitte des ganzen leiblich-seelisch-geistigen Gebildes, das wir "Mensch" nennen...".

6 CI 81 SB: «und sie dadurch vor mancher Beängstigung und Verwirrung zu behüten, durch die sie selbst sich hatte hindurchkämpfen müssen». 
sas «moradas» existentes en este «edificio», es decir, a una interioridad diversificada.

Respecto a tal interioridad, «las moradas», resulta significativa la exhortación que Edith Stein emite a continuación, cuando acota: «no hay que imaginarlas en fila, una detrás de otra,... «sino poned los ojos en el centro, que es la pieza adonde está el rey, y considerad como un palmito, que para llegar a lo que es de comer tiene muchas coberturas que todo lo sabroso cercan» ${ }^{7}$. Emerge aquí una forma práctica de enfocar la diversidad de las «moradas», que resulta muy relevante dogmáticamente, ya que por el no al "en fila» la autora evita una secuencia cuantitativa en el proceso formativo y se centra más bien en la dimensión cualitativa teológica relevante al insistir en "poned los ojos en el centro». Desde este centro, pues, que a la vez es el punto antropológico más profundo y el lugar teológico propiamente tal en cuanto "pieza del rey», el educando llega "a lo que es de comer», es decir, a satisfacer sus necesidades humanas vitales.

Esta posibilidad prometedora es contrarrestada por la autora, luego, con la realidad concreta, cuando afirma: «Pero, de hecho, hay muchas almas así, "...tan enfermas y mostradas a estarse en cosas exteriores, que no ha remedio ni parece que pueden entrar dentro de sî" ${ }^{8}$, una constatación que evoca el crudo realismo del educar, pero también justifica el esfuerzo invertido para revertir el hecho de que " "la costumbre la tiene tal de haber siempre tratado con las sabandijas y bestias que están en el cerco del castillo, que ya casi está hecha como ellas..." "”. El asimilarse del hombre al ser de las bestias, que aquí emerge, es provocador, pero un tema teológico de mucha envergadura y analizado, detenidamente, por los Padres de la Iglesia, como Gregorio de Nisa. Resalta, pues, no solo el dinamismo hacia el mal, que revierte el ideal del proceso formativo,

CI 81 SB 41: «Die Wohnungen sind nicht in einer Reihe zu denken, "sondern ihr müßt eure Augen auf den Mittelpunkt, d. i. auf das Gemach oder den Palast, in welchem der König wohnt, richten und euch denselben vorstellen wie die schmackhafte Frucht des Palmenbaumes, welche viele Schalen hat, die man”».

8 CI 82: SB 41: «Aber tatsächlich sind viele Seelen "so krank und mit äußerlichen Dingen sich so zu beschäftigen gewohnt ..., daß es ihnen unmöglich scheint, in ihr Inneres einzukehren"».

9 CI 82 SB: «Denn die Gewohnheit, immer mit den.kriechenden und andern Tieren, welche sich um die Burg herum aufhalten, umzugehen, hat sie diesen fast gleich gemacht». 
a modo del paraíso perdido por la caída -pérdida visible en efectos tan atroces como el "hacerse bestia», es decir, morir-, sino también la privación de un ideal, que en cuanto anhelo de plenitud no puede borrarse. Recuperar paso a paso tal plenitud es, sin duda, tarea eminente del educar que debe partir del "conocerse a sí mismo».

\section{b. El conocerse a sí mismo, sostenido por el amor gratuito}

El primer paso de esta recuperación consiste, desde muy antiguo, en el "conocerse a sí mismo», es decir, entrar en sí mismo, «a través de la puerta», «la primera morada». Explica Edith Stein, siguiendo a Teresa: «Por eso la primera morada a la que se entra a través de la puerta, es el conocimiento de si mismo... Mediante el propio conocimiento nos acercamos a Dios. Por eso nunca es superfluo, ni siquiera cuando se ha llegado a las moradas internas ${ }^{10}$. El conocimiento de sí mismo entonces es básico para conocerse a "sí mismo», pero también a «Dios», hasta tal punto que su relevancia se hace presente en todo el proceso formativo, es decir, en sus avances hacia adentro, sobre todo, cuando se toma en cuenta que en la primera morada «El alma está aún tan enredada en las cosas de este mundo que no puede reflexionar sobre sí misma, sin pensar a la vez en las cosas que la tienen sujeta. Por eso la luz se oscurece para ella. No nota la presencia de Dios, ni siquiera cuando habla con Él, y rápidamente es empujada hacia afuera» ${ }^{11}$.

Los dos momentos señalados por la autora -la entrada hacia adentro y el peligro de ser empujada hacia afuera- ponen de relieve la comprensión profundamente teológica del hecho, captado por Edith Stein con singular nitidez, es decir, "Las potencias deben emplearse en Dios, con

10 CI 82 SB 42: «Und darum ist die erste Wohnung, in die man durch die Pforte gelangt, die der Selbsterkenntnis. Man kann nicht die Augen zu Gott erheben, ohne sich der eigenen Niedrigkeit bewußt zu werden. Gotteserkenntnis und Selbsterkenntnis stützen sich gegenseitig. Durch die Selbsterkenntnis nähern wir uns Gott. Darum wird sie niemals überflüssig, wenn man auch schon in die inneren WOhnungen gelangt ist».

11 CI 82 SB 2: «Die Seele ist noch so verstrickt in die Dinge dieser Welt, daß sie sich selbst nicht betrachten kann ohne das, was sie gefesselt hält, mitzubetrachten. Darum ist das Licht für sie verdunkelt. Sie merkt von der Gegenwart Gottes nichts, auch wenn sie zu ihm redet, und wird bald wieder nach außen gezogen». 
su propio (18) esfuerzo, mientras pueden actuar libremente» ${ }^{12}$. Resulta así indispensable el propio esfuerzo del educando, pero el agregado «en Dios» garantiza que sea un «actuar libremente». Esta afirmación casi paradójica evoca la temática compleja y profundamente católica del «mérito», que el Concilio de Trento formula bellamente cuando constata: «la bondad de Dios es tan grande que quiere que sean méritos nuestros lo que son dones de Dios»-DH 1574.

La unión del hombre con Dios, así diseñada como no proporcional, pero fundamental para el proceso formativo, no hace necesaria «la suspensión de las potencias", pero sí que "“os es necesario que muera el gusano, y más (30) a nuestra costa. Porque acullá ayuda mucho para morir el verse en vida tan nueva; acá es menester que viviendo en esta, le matemos nosotras"»-5M 3, $5^{13}$-. El morir al mal -el gusano- no cuestiona la bondad fundamental de la criatura, pero sí es su tarea urgente "matarlo» para que surja la vida nueva anhelada ${ }^{14}$ por el sujeto en formación por el sometimiento total de su voluntad a la de Dios, ya que comenta la autora: «Estar del todo unidos con la voluntad de Dios, significa "ser perfectos" y para esto "solas estas dos cosas nos pide el Señor: amor de Su Majestad y del prójimo: es en lo que debemos trabajar. Guardándolas con perfección, hacemos su voluntad, y así estaremos unidos con Él”» $-5 \mathrm{M} \mathrm{4}, 7^{15}$. El amor a «Él» y «al prójimo» es entonces la condición de posibilidad del proceso formativo, que aquí se expresa en actitudes como el "estar unidos», "ser perfectos», "trabajar», "guardarnos», actitudes que siempre apuntan a "otro", en la medida en que se realizan a partir de

12 CI 85 SB 45: «Die Kräfte sollen sich durch eigenes Bemühen mit Gott beschäftigen, solange sie ungehindert tätig sein können».

13 CI 89 SB 50: «Aber "sterben muß der Seidenwurm und zwar mehr als dort auf eigene Kosten. Denn dort wird das Sterben durch das neue Leben, welches die Seele gewonnen hat, sehr erleichtert; hier aber, wo sie noch ganz ihr altes Leben hat, muß sie selbst den Wurm ertöten"».

14 La vida es sin duda una categoría bíblica teológica muy bien acogida por Edith Stein. Cf. R. KÜHN, «Leben aus dem Sein. Zur philosophischen Grundintuition Edith Steins», Freiburger Zeitschrift für Philosophie und Theologie 35 (1988), 159-173.

15 CI 89; SB 50: «Mit dem Willen Gottes ganz vereint, heißt vollkommen sein, und dazu "verlangt der Herr nur zwei Stücke von uns: die Liebe zu Seiner Majestät und die Liebe zum Nächsten. Diese doppelte Liebe also zu üben, müssen wir uns Mühe geben; denn dann, wenn wir hierin vollkommen unsere Pflicht erfüllen, tun wir den Willen Gottes und werden so eins mit ihm sein"». 
«sí mismo». Pero pese a la insistencia en lo que le compete al educando respecto al amor fundante del proceso, la autora recalca la superioridad del amor que Dios nos tiene y que como tal posibilita lo «del hombre», cuando advierte " "porque es tan grande el que Su Majestad nos tiene, que en pago del que tenemos al prójimo hará que crezca el que tenemos a Su Majestad por mil maneras"»-5M 4, $8^{16}$, un crecimiento multifacético, primer atisbo de una gratuidad «desbordante».

Pero, más allá de la función desbordante, a la vez fundante del amor, Edith Stein subraya que la unión del hombre con Dios sea estable y duradera, lo que «se le concederá solo en la morada séptima, y todavía el alma es probada con los más intensos sufrimientos, externos e internos. Sobrevienen pues violentas tormentas interiores, que podrían compararse únicamente con las pruebas de los condenados y a los que solo Dios puede poner fin. Esto ocurre ciertamente porque «a deshora, con una palabra sola suya o una ocasión que acaso sucedió, lo quita todo tan de presto, que parece no hubo nublado en aquel alma... (34) y como quien se ha escapado de una batalla peligrosa con haber ganado la victoria queda alabando a nuestro Señor, que fue el que peleó... y así conoce claramente su miseria y lo poquísimo que podemos de nosotros si nos desamparase el Señor»-6M 1, 10 17 . El conocimiento de sí mismo entonces se ve sumergido en la "propia miseria", que a su vez incita a la acción, a batalla, es decir, sacar adelante el proceso formativo, educar.

Por eso, la autora sintetiza la primera entrada al conocimiento de sí mismo como "un fin que no consiste solo en la "divinización de las almas", sino que todas las gracias deben servir "para fortalecer nuestra

16 CI 90: CI 89: SB 50 «Denn der Herr liebt uns so sehr, daß er zur Belohnung der Liebe, die wir zum Nächsten tragen, unserer Liebe zu ihm auf tausendfältige Weise Wachstum verleiht».

17 CI 90. SB 51: «...die ihr erst in der siebenten Wohnung gewährt werden soll, und sie wird noch durch die härtesten äußeren und inneren Leiden erprobt. Sie wird von den heftigsten inneren Stürmen heimgesucht, die nur mit den Peinen der Verworfenen zu vergleichen sind und denen nur Gottein Ende machen kann. Das geschieht freilich, und zwar indem der Herr "unerwartet mit einem einzigen Wort, das er spricht oder durch einen Zufall, den er herbeiführt, alles so plötzlichverscheucht, als wäre in der Seele keine trübe Wolke gewesen ... Wie ein Kämpfer, der siegreich aus einer gefährlichen Schlacht hervorging, lobpreist die Seele unseren Herrn; denn er ist es, der den Sieg erfocht. Sie sieht ganz klar ein, daß nicht sie selbst gekämpft ... und so erkennt sie denn deutlich ihre Armseligkeit und wie wenig wir aus uns selbst vermögen, wenn der Herr seine Hand uns entzieht"». 
flaqueza... para poder imitar a Cristo en el mucho padecer", y trabajar sin descanso por el Reino de Dios. Para esto es la oración...; de esto sirve este matrimonio espiritual: de que nazcan siempre obras, obras» ${ }^{18}$. Más que en una contemplación sosegada, ajena al mundo circundante, el educar requiere obras, es decir, un actuar coherente con sus propias necesidades, pero anticipado y desbordado por un amor mayor.

c. El autodesarrollo creativo del espíritu -la Selbstzeugung- en cuanto regalo de Dios

Si bien puede temerse por la autonomía del sujeto bajo la influencia desbordante del amor gratuito, el educar apunta precisamente a esta autonomía, una Selbstzeugung, en cuanto proceso formativo. De hecho requiere reentradas permanentes en sí mismo, maduración y autoafirmación "creativa» desde el interior, que descubre el ser propio en contraste con la formación desde afuera, que lo encubre, pues afirma Edith Stein: "Otro impulso a reentrar en sí mismo se da, por pura experiencia, en el crecimiento de la persona durante el período de maduración que va desde la infancia a la juventud. Las sensibles transformaciones interiores impulsan por sí mismas a esta autoobservación. Pero con ese genuino y sano anhelo de conocerse, suscitado por el descubrimiento del "mundo interior", se mezcla de ordinario un impulso excesivo a la "autoafirmación". Y esto se convierte en una nueva fuente de ilusión que origina una falsa "imagen" del propio yo. A esto se añade el que en este período comienza la meditación (66) de sí mismo basada en la imagen que los otros ven desde fuera, y por tanto una formación del alma desde lo exterior, que conlleva el encubrimiento del propio ser» ${ }^{19}$.

18 CI 99: SB 61: «...Vielmehr sollen alle Gnaden "zur Stärkung unserer Schwachheit dienen, damit wir dem Herrn durch Ertragung vieler Leiden nachfolgen”.. und rastlos für das Reich Gottes wirken. "Dahin zielt das innerliche Gebet und dazu dient auch die geistige Vermählung, daß unaufhörlich Werke, lauter Werke daraus hervorgehen"».

19 Ee 103: SB 63: «Ein anderer Antrieb zur Hinwendung auf das eigene Selbst ergibt sich erfahrungsgemäß rein durch das Erstarken des Eigenwesens in der Zeit des Reifens vom Kinde zum Jugendlichen. Die spürbaren Wandlungen im Innern lenken von selbst den Blick darauf hin. Aber mit dem echten und gesunden Verlangen nach Selbsterkenntnis, das die Entdeckung dieser inneren Welt weckt, mischt sich gewöhnlich ein übersteigerter Drang, dieses Selbst zur Geltung zu bringen. Das wird wiederum zu einer Täuschungsquelle, die ein falsches Bild des eigenen Selbst erstehen läßt. Dazu kommt, daß sich zu dieser Zeit längst jene 
Para verificar este hecho, Edith Stein discute con Pfänder, al afirmar: "Partiendo de una descripción de los movimientos del alma, Pfänder trata de comprender la vida del alma misma, descubriendo los impulsos fundamentales, intenta él reconducirlos a un impulso originario: a la tendencia del alma al autodesarrollo, tendencia basada en la esencia misma del alma. Él ve en el alma un núcleo de vida que partiendo de ese germen debe desarrollarse hasta tener forma plena. Pertenece a la propia esencia del alma humana el que, para su propio desarrollo, sea necesaria la libre actividad de la persona. Sin embargo, el alma es "esencialmente creatura y no creadora de sí misma. No se genera a sí misma, sino que únicamente puede desarrollarse. En el punto más profundo de sí misma (cara atrás) está ligada (70b) a su perenne principio creativo. A partir de él puede procrear-auszeugen - en plenitud, únicamente manteniéndose estable en contacto con ese perenne principio creador" $"{ }^{20}$.

La tendencia al autodesarrollo creativo, descrita así por Edith Stein, vuelve al hecho que «El centro del alma es el lugar desde donde se hace oír la voz de la conciencia, y el lugar de la libre decisión personal. Por eso y porque la libre decisión de la persona es condición requerida para la unión amorosa con Dios, ese lugar de las libres opciones debe ser también el lugar de la libre unión con Dios. Esto explica por qué santa Teresa (al igual que otros maestros espirituales) veía la entrega a la voluntad de Dios como lo más esencial en la unión: la entrega de nuestra voluntad es lo que Dios nos pide a todos y todos podemos realizar. Ella es la medida de nuestra santidad, y a la vez la condición para la unión

Betrachtung des eigenen Selbst unter dem Bilde, wie es die andern von außen sehen, angebahnt hat, ja selbst eine Formung der Seele von außen her, und zur Verdeckung ihres eigent- lichen Wesens beiträgt».

20 CI Es 105 Ee 103: ED 522s: «Pfänder Von einer Beschreibung der seelischen Regungen ausgehend, bucht Pfänder das Verständis des seelischen Lebens durch Aufdeckung der es beherrschenden Grundtriebe zu erschliessen. Diese Grundtriebe führt er auf einen Urtrieb zurück: den Trieb der Seele nach Selbstauszeugung, der im Wesen der Seele begründet ist. Er sieht in der seele ein Lebewesen, das sich aus einem Keim zur Vollgestalt auszeugen muss.Es gehört zum eingentümlichen Wesen der Menschenseele, dass zu ihrer Auszeugung freie persönliche Tätigkeit nötig ist. Sie ist aber "wesentlich Geschöpf und nicht der Schöpfer ihrer selbst. Sie erzeugt nicht sich selbst, sondern sie kann sich selbst nur auszeugen. Im tiefsten Punkt ihrer selbst ist sie nach rückwärts verbunden mit dem dauernd schöpferischen Grund ihrer selbst. Sie kann sich selbst daher nur voll auszeugen, indem sie dauernd in Kontakt bleibt mit dem dauernd schöpfereischen Grund"». 
mística que no está en nuestro poder, sino que es libre regalo de Dios» ${ }^{21}$. El autodesarrollo es entonces fundamentalmente regalo libre de Dios, es decir, la libertad humana solo es libre si el espíritu del hombre es liberado por la gracia.

Pero el espíritu liberado del ser humano en el mundo no es espíritu puro y solo en cuanto unido con el alma y a su vez con el cuerpo vivo es sujeto del autodesarrollo que aspira el proceso formativo del educar. Se trata de un hecho fundamental, al cual Edith Stein se muestra muy sensible, tal como lo afirma, cuando insiste: «el espiritu y alma son una sola cosa, y, sin embargo, se distinguen entre sí... En correspondencia con esas diferencias hemos encontrado en el alma humana diversos (77) modos de ser: como forma del cuerpo el alma toma forma en una materia que le es extraña y con ello sufre el obscurecimiento y el gravamen que consigo trae la vinculación a la materia pesada (la materia en el estado de caída). Pero el alma a la vez se realiza y se manifiesta como ser personalespiritual en cuanto fluye en la vida libre y consciente y se eleva al reino luminoso del espíritu, y cuanto más hondamente el alma se sumerge en el espíritu y más firmemente se instala en su centro, tanto más libremente puede elevarse sobre sí misma y liberarse de las ataduras materiales: hasta romper los lazos que unen el alma y el cuerpo terreno -como sucede en (79) la muerte, y en cierto sentido también en el éxtasis-, y hasta la transformación del "alma viviente" en el "espíritu que da la vida", que es capaz desde sí mismo de formar un "cuerpo espiritual" ${ }^{22}$.

21 SB 67s: «Der Mittelpunkt der Seele ist der Ort, von dem aus die Stimme des Gewissens sich vernehmen läßt, und der Ort der freien persönlichen Enscheidung. Weil es so ist und weil zur liebenden Vereinigung mit Gott die freie persönliche Hingabe gehört, darum muß der Ort der freien Entscheidung zugleich der Ort der freien Vereinigung mit Gott sein. Von hier aus wird es iuch verständlich, Warum von der heiligen Mutter Teresia (ebenso wie von anderen Geisteslehrern) die Hingabe des Willens an den göttlichen als das Wesentlichste an der Vereinigung angesehen wird: die Hingabe unseres Willens ist das, was Gott von uns allen verlangt und was wir leisten können. Sie ist das Maß unserer Heiligkeit. Sie ist zugleich die Bedingung der mystischen Vereinigung, die nicht in unserer Macht steht, sondern freies Geschenk Gottes ist».

22 CI Ee: 106: SB 68: «daß Geist und Seele eins sind und doch wiederum voneinander zu scheiden. Sodann fanden wir -diesen Unterscheidungen entsprechend- an der Menschenseele verschiedene Seinsrichtungen: als Form des Leibes gestaltet sie sich in einen ihr fremden Stoff hinein und erleidet dabei die Verdunkelung und Belastung, die die Bindung an massenbeschwerten Stoff (den Stoff im Zustand des Falles) mit sich bringt 100 Sie gestaltet zugleich sich selbst aus und offenbart 
Finaliza la autora la dilucidación del autodesarrollo del espíritu con una advertencia de singular importancia teológica, diciendo que tal autodesarrollo «a la vez significa la progresiva adquisición de una posición cada vez más nítida y objetiva frente al mundo. Si para poder llegar a Dios, es necesario liberarse plenamente de las ataduras pecaminosas que nos ligan a las cosas del mundo, ese sustraerse no es meta, sino camino. La conclusión viene a demostrar que, al fin, se restituyen al alma todas sus fuerzas naturales para que pueda trabajar en el servicio del Señor ${ }^{23}$. Tal restitución, sin duda, es un proceso complejo, pero que se centra en la interioridad articulada en la experiencia.

\section{LA EXPERIENCIA DEL MUNDO INTERIOR Y SU RELEVANCIA FORMATIVA}

No cabe duda de que Edith Stein, en la medida en que avanza con su Comentario al Castillo Interior, centra su atención primordial en la constitución del alma en cuanto espacio de interioridad asequible y moldeable por la experiencia, ligada a la vivencia, siendo la experiencia uno de los conceptos teológicos más difíciles y menos explorados por la Teología Sistemática, aunque actualmente conocemos aportes significativos a su comprensión ${ }^{24}$, pero de suma relevancia práctica, ya que plasma una inmediatez de la verdad de la realidad, que se va aprendiendo en el viaje desde el interior del alma.

sich dabei als persönlich -geistiges Wesen, indem sie in frei- bewußtem Leben ausströmt und sich in das Lichtreich des Geistes erhebt, ohne daß sie aufhörte, verborgener Quell zu sein. Dieser verborgene Quell...im Sinne de.r inhaltlichen Scheidung von Stoff und Geist ein Geistiges, und je tiefer die Seele in ihn hinabsteigt und je mehr sie sich in ihrem Mittelpunkt befestigt, desto freier kann sie über sich emporsteigen und sich aus der Stoffverhaftung lösen: bis zur Durchschneidung des Bandes zwischen Seele und irdischem Leib -wie sie im Tode, in gewisser Weise aber schon in der Ekstase eintritt- und zur Wandlung der lebendigen Seele in einen lebenspendenden Geist».

23 CI 100: SB 62: «Es bedeutet aber zugleich das fortschreitende Erringen einer immer reineren und Sachgemäßeren Einstellung zur Welt. Wenn die sünd- hafte Verstrickung in die Dinge der irdischen Welt zunächst eine vollständige Loslösung von ihnen fordert, um zu Gott gelangen zu können, so ist die Entrückung nicht Ziel, sondern Weg. Das Ende zeigt ja, daß der Seele schließlich ihre ganze natürliche Wirkungskraft wiedergegeben wird, um im Dienst des Herrn arbeiten zu können».

24 Cf. H. U. Von Balthasar, Gloria I. 
a. El alma, punto de arranque y escenario de experiencias gratuitas

Desde siempre resulta difícil definir el alma, aunque el esfuerzo por lograrlo ha sido permanente. Por eso Edith Stein admite «no es posible ofrecer un cuadro preciso del alma -ni tan siquiera de forma somera y deficiente- sin llegar a hablar de lo que compone su vida íntima. Por ello, las experiencias fundamentales sobre las cuales hemos de basarnos son los testimonios de los grandes místicos de la vida de oración. Y en tal calidad, el "Castillo interior» es insuperable; ya sea por la riqueza interior de la autora, que cuando escribe ha llegado al más alto grado de vida mística; ya sea por extraordinaria capacidad de expresar en términos inteligibles sus vivencias interiores, hasta hacer claro y evidente lo inefable, y dejarlo marcado con el sello de la más alta veracidad; ya sea por la fuerza que hace comprender su conexión interior y presenta el conjunto en una acabada obra de $\operatorname{arte»}^{25}$. Junto con admitir la dificultad de precisar lo que es el alma, la autora señala aquí los elementos que posibilitan tal precisión, la vida íntima y el acceso a su interioridad por medio de la experiencia.

Pero previo a abordar la experiencia, es decir, «los sucesos que acaecen en el interior del hombre» ${ }^{26}$, es necesario para Edith Stein, interpretando a Teresa, «aclararse a sí misma en qué consiste exactamente ese mundo interior». Según Edith Stein, Teresa logra esta aclaración porque «se le ocurrió la feliz imagen de un castillo con muchas moradas y aposentos ${ }^{27}$, una imagen que contrasta el mundo interior al exterior,

25 CI 80 SB 39: «Es ist aber unmöglich, ein treffendes (wenn auch noch so flüchtiges und unzulängliches) Bild der Seele zu geben, ohne auf das zu sprechen zu kommen, was ihr innerstes Leben ausmacht. Die Erfahrungsgrundlage, auf die wir uns dabei zu stützen haben, sind die Zeugnisse großer Mystiker des Gebetslebens; als solches Zeugnis ist die Seelenburg unübertroffen: durch den Reichtum an innerer Erfahrung, über den die heilige Verfasserin verfügte, da sie die höchste Stufe des mystischen Gnadenlebens erreicht hatte; durch ihre ungewöhnliche Fähigkeit, sich über die Vorgänge in ihrem Innern verstandesmäßig Rechenschaft zu geben, fast Unsagbares klar und anschaulich und mit dem Stempel Iauterster Wahrhaftigkeit zum Ausdruck zu bringen; durch. die Kraft, die einzelnen Tatsachen in ihrem inneren Zusammenhang zu begreifen und die Darstellung dieses Zusammenhangs zu einem geschlossenen Kunstwerk zu gestalten».

26 CI 81 SB 39: «ie Vorgänge im Innern des Menschen verständlich zu machen».

27 CI 81 SB 39: «ohne sich darüber zu erklären, was denn eigentlich dieses Innere sei». CI 81 SB 39: «Dafür bot sich ihr das glückliche Bild einer Burg mit vielen Wohnungen und Gemächern». 
pues, «Fuera del mundo de las murallas que rodean el castillo, se extiende el mundo exterior; en la estancia más interior habita Dios» ${ }^{28}$. De tal modo que «entre estos (que, como es obvio, no han de entenderse espacialmente), se hallan las seis moradas que circundan la más interior (la séptima) $»^{29}$. Pero sucede que «los moradores que andan por fuera o que se quedan junto al muro de cerca, no saben nada del interior del castillo ${ }^{30}$, por lo cual urge iniciar el proceso de educar, que más que una iniciativa humana está condicionada a Dios y sus llamadas.

En este sentido, Edith Stein comenta de modo acertado lo que Teresa designa como las llamadas de Dios. «No se trata de voces interiores, que se hagan sentir en el alma misma, sino de reclamos que le vienen desde fuera y que ella percibe como un mensaje de Dios» ${ }^{31}$. Resalta la negación de la importancia de los sentidos -el oír interior-, el sentir en el alma misma, que hace recordar la epoché, este poner entre paréntesis las apariencias del mundo natural y sus múltiples expresiones pues, comenta Edith, aunque «el alma vive todavía en y con el mundo; pero estas llamadas penetran en su interior y la invitan a entrar dentro de sí $\aleph^{32}$. Esta invitación, sin duda, de mayor relevancia para el proceso formativo se articula a través de los pasos concretos que la autora describe detenidamente en cuanto entrada progresiva en sí misma.

\section{b. LOS PASOS CONCRETOS DE LA ENTRADA HACIA ADENTRO}

Una vez descrito el espacio interior, el alma, en lo que se refiere a los sucesos que allí acontecen en cuanto experiencias, Edith Stein, siguiendo a Teresa, explica «otra fuente», que atestigua la interiorización creciente, constatando: «Hay otra fuente (el alma en la oración de quietud) a la

28 CI 81s SB 40: «Außerhalb der Ringmauern dehnt sich die äußere Welt, im ionersten Gemach wohnt Gott».

29 CI 81s SB 40: «Dazwischen (was natürlich nicht räumlich zu verstehen ist) liegen die sechs Wohnungen, die das Innerste (die siebente) umgeben».

30 CI 82 SB 41: «Die Bewohner aber pflegen draußen herumzu- schwärmen oder sich in den Ringmauern aufzuhalten, sie wissen vom Innein der Burg nichts».

31 CI 82s SB 42: «Es sind darunter nicht innere Einsprechu:ngen zu verstehen, die sich in der Seele selbst bemerkbar machen, sondern etwas, was von außen an sie herantritt, was sie aber als eine von Gott geschickte Mahnung auffaßt».

32 CI 83 SB 42: «Die Seele lebt immer noch in und mit der Welt, aber diese Rufe dringen in ihr Inneres ein und mahnen sie selbst zur Einkehr». 
que "viene el agua de su mismo nacimiento, que es Dios, y así cuando Su Majestad quiere hacer al alma alguna merced sobrenatural, produce con grandísima paz y quietud y suavidad de lo muy interior de nosotros mismos, yo no sé hacia dónde ni cómo... ni aquel contento y deleite se siente como los terrenos en el corazón -digo en su principio, que después todo lo hinche-, vase revertiendo esta agua por todas las moradas y potencias hasta llegar al cuerpo; que por eso dije que comienza de Dios y acaba en nosotros; que por cierto, como verá quien lo hubiese probado, todo el hombre exterior goza de este gusto y suavidad" " $-4 \mathrm{M} 2,4^{33}$-. Tal "gusto y suavidad» va acompañado de "una fragancia», que la autora describe así: «El alma siente "una fragancia... como si en aquel hondón interior estuviese un brasero adonde se echasen olorosos perfumes: ni se va la lumbre, ni adonde está; mas el calor y humo oloroso penetra toda el alma..." $-4 \mathrm{M} 2,6^{34}$.

Las experiencias íntimas descritas a partir de los «sentidos» del alma, concebidas analógicamente a los sentidos corporales, se articulan en clave temporal de la siguiente manera, "Dicen que 'el alma se entra dentro de

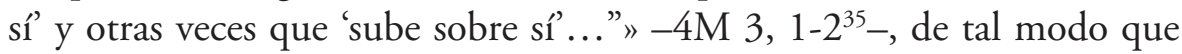
"Transcurren días y años, hasta que por fin, viendo su perdición, se han ido acercando al castillo sin lograr entrar dentro; ya no son traidores, y merodean alrededor, pues es recia cosa y difícil de vencer esa su costumbre

33 CI 85 SB 43: «Der andere Brunnen (die Seele im Gebet der Ruhe) nimmt das Wasser unmittelbar von der Quelle selbst, die Gott ist, in seinen Behälter auf, und darum geschieht es, wenn es Seiner Majestät gefällt, der Seele eine übernatürliche Gnade "mitzuteilen", im höchsten Frieden, mit größter Ruhe und Süßigkeit, ganz in unserm Innern selbst, ich weiß nicht, wo und wie. Die Freude und Wonne wird nicht, wie die irdischen, gleich anfangs im Herzen empfunden, erst später füllt dieses Wasser alles an und ergießt sich durch alle Wohnungen und Kräfte der Seele, bis es sich auch über den Leib ausbreitet. Deshalb sagte ich, die geistigen Süßigkeiten fangen in Gott an und endigen in uns, indem in Wahrheit der ganze äußere Mensch sie genießt».

34 CI 84 SB 44 «Sie spürt ... einen gewissen Wohlgeruch, als wäre in jener inneren Tiefe ein Feuerbecken,worauf man wohlriechendes Räucherwerk gestreut. Zwar ist weder das Feuer noch die Stätte sichtbar, wo es brennt; aber die Wärme und der liebliche Geruch durchdringen die ganze Seele ...».

35 CI 84SB 44: «Man sagt, die Seele gehe in sich selbst ein oder sie erhebe sich über sich selbst». 
de vagar fuera de casa ${ }^{36}$. Pero acontece algo imprevisto y gratuito, es decir, una intervención de «otro», ciertamente suave, a modo de «un silbo", pero fuerte, pues constata Edith Stein: «"tiene tanta fuerza este silbo del pastor, que desamparan las cosas exteriores en que estaban enajenados, y métense en el castillo... Porque para buscar a Dios en lo interior (que se halla mejor y más a nuestro provecho, que en las criaturas...), es gran ayuda cuando Dios hace esta merced"” -4 M 3, 2-337. Resulta decisiva la ayuda de Dios y de su «merced», para que el educando pueda dar los pasos necesarios y libres durante el proceso formativo de interiorización.

Pero advierte Edith Stein con razón: «No se piense que este interiorizarse se adquiere con el entendimiento "procurando pensar dentro de sí a Dios, ni por la imaginación... antes que se comience a pensar en Dios, ya esta gente está en el castillo, que no sé por dónde ni cómo oyó el silbo del pastor, que no fue por los oídos -que no se oye nada-; más siéntese notablemente un encogimiento suave a lo interior, como verá quien pasa por ello..."”-4M 3, $3^{38}$-. Una falta básica de entendimiento, que sin embargo, hace entender, queda luego subrayada por la autora de la siguiente manera: «Durante el breve espacio de la unión, el alma no comprende lo que le ocurre, pero "fija Dios a sí mismo en lo interior de aquel alma de manera que cuando torna en sí en ninguna manera pueda

36 CI 85: CI 84: SB 44: «Es vergehen Tage und Jahre, da endlich sehen sie ihr Verderben einund nähern sich wieder der Burg, ohoe es jedoch fertigzubringen, in das Innere derselben zurückzukehren; denn sind sie auch keine Verräter mehr und schweifen sie nur noch um die Burg herum, so ist doch diese Gewohnheit des Herumschweifens schwer zu überwinden».

37 CI 85 SB 45: «Dieses Pfeifen des Hirten hat eine solche Kraft, daß sie die äußeren Dinge, in die sie sich verirrt hatten, verlassen und sich in die Burg begeben... W enn Gott diese Gnade gewährt, ist er der Seele in ganz besonderer Weise behilflich, ihn in ihrem eigenen Ionern zu suchen. Dort findet sie ihn weit besser und mit mehr Nutzen als in den Geschöpfen außer sich».

CI 85 SB 45: «Man darf nicht etwa denken, «diese Sammlung werde durch den Verstand erworben, indem man sich bemüht, in seinem Ionern sich Gott als gegenwärtig zu denken, oder durch die Einbildungskraft, indem wir uns ihn in uns selbst vorstellen ... Was ich hier meine, geschieht in ganz anderer Weise, und manchmal finden sich die Sinne und Kräfte der Seele, noch ehe man beginnt an Gott zu denken, schon in der Burg, sodaß man nicht weiß, wie sie hineingekommen sind oder wie sie das Pfeifen ihres Hirten vernommen haben, da nichts davon zu den Ohren gedrungen; denn man hört nichts davon, merkt aber deutlich eine sanfte Zurückziehung in das Innere, wie diejenigen es erfahren werden, denen dies Gebet zuteil wird». 
dudar que estuvo en Dios y Dios en ella. Con tanta firmeza le queda esta verdad, que aunque pase años sin tornarle Dios a hacer aquella merced, ni se le olvida ni puede dudar que estuvo"»-5M 1, 9-. "El alma jamás ve este secreto misterioso mientras se realiza en ella, pero "lo ve después claro; y no porque es (23) visión, sino una certidumbre que queda en el alma, que solo Dios la puede poner"»-5M 1, $10^{39}$.

Opuestas a la paz y suavidad descritas hasta el momento, la autora evoca experiencias distintas tales como: "Sobrevienen pues violentas tormentas interiores, que podrían compararse únicamente con las pruebas de los condenados y a los que solo Dios puede poner fin ${ }^{40}$, tormentas ciertamente violentas, pero que acontecen con una finalidad significativa, pues acota Edith Stein, «Verdaderamente el alma "parece que ya no ha menester consideración para entender esto, porque la experiencia de pasar por ello, habiéndose visto del todo inhabilitada, le hacía entender

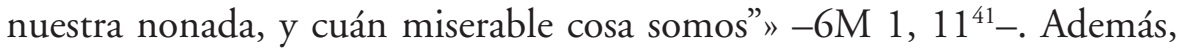
«En medio de todos estos sufrimientos al alma no se le oculta cuán cercana está del Señor. Él se hace sentir mediante "unos impulsos tan delicados y sutiles que proceden de lo muy interior del alma..." " ${ }^{42}$, hasta tal punto que el alma "“...Siente (36) ser herida sabrosísimamente, mas no atina cómo ni quién le hirió; más bien conoce ser cosa preciosa y jamás querría ser sana de aquella herida” ${ }^{43}$, una experiencia paradójica, que, sin embar-

39 CI 87 SB 45: «Während der kurzen Dauer der Vereinigung versteht die Seele nicht, was mit ihr geschieht. «Aber Gott drückt sich selbst der Seele in einer Weise ein, daß sie, wenn sie wieder zu sich kommt, durchaus nicht zweifeln kann, sie sei in Gott und Gott in ihr gewesen. Diese Wahrheit bleibt ihr mit einer solchen Festigkeit, daß sie dieselbe, auch wenn Gott jahrelang ihr diese Gnade nicht wieder erweist, doch nie vergißt und nie daran zweifeln kann ... ».

40 CI 90 SB 51: «Sie wird von den heftigsten inneren Stürmen heimgesucht, die nur mit den Peinen der Verworfenen zu vergleichen sind und denen nur Gottein Ende machen kann».

41 CI 91 SB: «Freilich bedarf die Seele "um zu dieserErkenntnis zu gelangen ... keiner Betrachtung mehr; denn nachdem sie sich so gänzlich unfähig gesehen, hat sie aus der Erfahrung unsere Armseligkeit und Nichtigkeit kennengelernt"».

42 CI 91 SB 52: «Bei all diesen Leiden bleibt es der Seele doch nicht verborgen, wie nahe sie dem Herrn bereits ist. Er macht sich bemerkbar durch "feine und zarte Antriebe, die vom Innersten der Seele ausgehen”".

43 CI 91 SB 52: «Sie fühlt sich auf das lieblichste verwundet, Ohne jedoch zu wissen, wie und von wem sie die Wunde empfangen; aber das erkennt sie gut, daß dieselbe etwas Kostbares ist, und sie möchte gar nie mehr davon geheilt werden». 
go, fortalece al educando para continuar el proceso emprendido a través de otras experiencias proporcionadas, señaladas por Edith Stein, cuando afirma: “"También suele nuestro Señor tener otras maneras de despertar el alma: que a deshora, estando rezando vocalmente y con descuido de cosa interior, parece viene una inflamación deleitosa, como si de presto viniese un olor tan grande que se comunicase por todos los sentidos" " ${ }^{44}$.

Luego evoca la autora «Un tercer modo "que tiene Dios de despertar el alma"». "Son ciertas hablas "de muchas maneras: unas parece que vienen de fuera, otras de lo muy interior del alma, otras de lo superior de ella"... Así por ejemplo, "está un alma en toda la tribulación y el alboroto interior... (39) y oscuridad del entendimiento y sequedad" ${ }^{45}$. Pero insiste en que "Todas estas palabras interiores, de que así se trata, no pueden menos de ser escuchadas por el alma, "porque el mismo Espíritu que me habla hace parar todos los otros pensamientos y advertir a lo que se dice" "46. Resalta aquí la acción del mismo Espíritu Santo, quien teológicamente está íntimamente ligado a la gracia y su gratuidad desbordante, sin identificarse con ella cuando se une con el espíritu del hombre, que para Edith Stein no se identifica con el alma, pero que abre la profundidad hacia afuera, siendo para algunos autores hoy, el concepto clave para entender a Edith Stein ${ }^{47}$.

Pese a los pasos concretos descritos por Edith Stein, de cuya relevancia para el proceso formativo no cabe duda, la autora comenta otro momento muy significativo, cuando explica: «A veces el alma es "tocada" en forma tal por una palabra de Dios que cae en éxtasis: "parece

44 CI 92 SB 53: «Der Herr pllegt noch auf andere Weisen die Seelen zu wecken. Unerwartet, und ohne an etwas Innerliches zu denken, scheint manchmal die Seele, während sie auch nur mündlich betet, von einer wonnevollen Entflammung erfaßt zu werden. Es kommt ihr da vor, als lasse sich plötzlich ein so starker Wohlgeruch (in ihr) wahrnehmen, daß er sich allen Sinnen mitteilt».

45 CI 92 SB 53: «Eine dritte Art sind "gewisse Ansprachen an die Seele, die von mannigfacher Art sind. Es scheinen nämlich einige ... von außen, einige ganz aus dem Ionern der Seele und wieder andere aus ihrem oberen Teil zu kommen"...z.B. die Seele, ganz erfüllt von Trübsal Und innerer Unruhe, in... Verfinsterung des Verstandes und Trockenheit des Geistes».

46 CI 93 SB 54: «Auf solche innere Ansprachen, um die es sich hier handelt, muß die Seele horchen, Denn da bringt der Geist selbst, welcher spricht, alle anderen Gedanken zum Schweigen und nötigt die Seele, das anzuhören, was er zu ihr spricht».

47 J. L. Caballero, Edith Stein (1891-1942), (Madrid 2001), 94. 
que Su Majestad desde lo interior del alma hace crecer la centella que dijimos ya, movido de piedad de haberla visto padecer tanto tiempo por su deseo, que abrasada toda ella como un ave fénix queda renovada y, piadosamente se puede creer, perdonadas sus culpas; (42) y así limpia, la junta consigo, sin entender aún aquí nadie sino ellos dos, ni aun la misma alma entiende de manera que lo pueda después decir, aunque no está sin sentido interior" ${ }^{48}$.

Luego continúa, «Al mismo tiempo, en el éxtasis ve el alma algo de las maravillas de esa especie de "aposento de cielo empíreo que debemos tener en lo interior de nuestra alma" ${ }^{49}$, lo cual significa "dejando abierta solo la morada en que Él está para introducir en ella el alma ${ }^{50}$ en "el gran éxtasis en que queda suspendida la actividad natural de los sentidos exteriores e interiores, al igual que la de las potencias, por lo general dura poco" ${ }^{51}$. Puede apreciarse aquí que la meta alcanzada a través de la experiencia del proceso de interiorización evoca un desborde que a la vez parece ser plenitud y ruptura, una cuestión abierta que queda por dilucidarse.

\section{LO QUE DESBORdA LA EXPERIENCIA INTERIOR: ¿RUPTURA O PLENIFICACIÓN?}

Después de haber diseñado los pasos concretos hacia el centro de sí mismo, Edith Stein ofrece una explicación del final del camino recorrido de

48 CI 93 SB 54: «Manchmal wird die Seele von einem Gotteswort so betroffen, daß sie in Verzückung gerät: "Es scheint, als ob der Herr, von Mitleid wegen der Leiden, die er sie so lange Zeit in ihrem Verlangen nach ihm erleiden sah, gerührt, aus ihrem Innern den schon besprochenen Funken auflodern ließe. Dadurch ganz verzehrt, geht sie dann, gleich dem Vogel Phönix, verjüngt aus der Glut hervor, und es ist fromm zu glauben, daß ihr ihre Sünden vergeben sind, vorausgesetzt, daß ihr die nötige Zubereitung nicht fehlte und daß sie die von der Kirche verordneten Mittel gebraucht hatte. Nachdem sie in solcher Weise rein geworden, vereinigt sie der Herr mit sich, und niemand außer ihnen beiden weiß davon, ja die Seele selbst erkennt es nicht in einer Weise, daß sie es nachher erklären könnte, obwohl sie nicht ohne innere Empfindung dabei ist ...”"».

49 CI 93 SB 54: «Zugleich schaut sie in der Verzückung etwas von den Herrlichkeiten jener "Wohnung des höchsten Himmels, die wir im Innern unserer Seele selbst haben müssen"».

50 CI 93 SB 54: «nur die des Gemaches, welches er selbst bewohnt, bleibt offen, damit wir in dasselbe eingehen können».

51 CI 94 SB 54: «Die große Ekstase, in der die natürliche Tätigkeit der äußeren und inneren Sinne sowie der geistigen Kräfte aufgehoben ist, dauert meist nicht lange». 
especial densidad formativa, tratándose del éxtasis. Afirma pues: «Sustancialmente es uno con el éxtasis, aunque "en el interior (del alma) se siente muy diferente", es lo que la Santa llama vuelo del espíritu, en que "muy de presto algunas veces se siente un movimiento tan acelerado del alma, que parece es arrebatado el espíritu con una velocidad que pone harto temor, en especial a los principios" " ${ }^{52}$. Dentro de este cuadro un tanto desconcertante de la máxima experiencia interior ligado al éxtasis, llama la atención que el concepto «espíritu» sustituye o complementa el del alma. Precisamente al "vuelo del espíritu» se encuentran ligados fenómenos sorprendentes con efectos gozosos.

\section{a. El traspaso de la «saeta de fuego» y su deleite desbordante}

Según Edith Stein, comentando a Teresa, sucede pues que "Con frecuencia, pensando en la tardanza de la muerte, se siente como traspasar por "una saeta de fuego... en lo muy hondo e íntimo del alma, adonde este rayo que de presto todo cuanto haya de esta tierra de nuestro natural y lo deja hecho polvos" ${ }^{53}$. Subraya la autora que «El matrimonio mismo tiene lugar "en el centro muy interior del alma, que debe ser adonde está el mismo Dios... en todo lo que se ha dicho hasta aquí, parece que va por medio de los sentidos y potencias, y este aparecimiento de la Humanidad del Señor así debía ser" ${ }^{54}$. Puede apreciarse aquí la meta alcanzada después de un camino recorrido escabroso, pero certero. Como tal resulta de especial relevancia para esclarecer el contenido de una experiencia universalmente feliz para todo educando, pero misteriosamente propio de cada uno.

52 CI 94 SB 56: «Dem Wesen nach mit der Verzückung eins, aber in seinem Verlauf im Innern ... in einer von dieser ganz verschiedenen Weise empfunden, ist das, was die Heilige Geistesflug nennt; wobei man "urplötzlich eine hastige Bewegung der Seele merkt und der Geist mit einer solchen Schnelligkeit dahingerissen zu werden scheint, daß man, besonders am Anfang, von grosser Furcht befallen wird"».

53 CI 95s:SB 57: «Oft fühlt sie sich beim Gedanken an das Säumen des Todes wie von einem feurigen Pfeil durchbohrt und "im tiefsten und innersten Grunde der Seele" verwundet, "wo dieser schnell vorübergehende Blitzstrahl alles zu Asche verbrennt, was er Irdisches von unserer Natur vorfindet"».

54 CI 97 SB 58: «Die Vermählung selbst, "geht im innersten Mittelpunkt der Seele vor sich, an dem Ort, wo Gott selbst wohnen muß. Meines Erachtens bedarf er auch keiner Tür, um da einzugehen ... ; denn bei allem bisher Besprochenen scheint er sich der Sinne und der Vermögen zu bedienen, und auch die erwähnte Erscheinung der Menschheit des Herrn muß wohl in dieser Weise geschehen sein"». 
De ahí que la autora subraya acertadamente: «"Es un secreto tan grande y una merced tan subida lo que comunica Dios allí al alma en un instante y el grandísimo deleite que siente el alma, que no sé a qué comparar, sino a que quiere el Señor manifestarle por aquel momento la gloria que hay en el cielo, por más subida manera que por ninguna visión ni gusto espiritual" " ${ }^{55}$. Pero hay más todavía, de especial importancia para la verificación de nuestra hipótesis, es decir, la índole desbordante que conllevan las experiencias relatadas y confirmadas por la autora, cuando comenta: «La corriente que se comunica al alma, se desborda desde lo más íntimo de sí a las potencias. "Se entiende claro que hay en lo interior... un sol de donde procede una gran luz que envía a las potencias, de lo interior del alma. Ella... no es muda de aquel centro ni se le pierde la paz" ${ }^{56}$.

Edith Stein concluye, de modo acertado, su comentario a las experiencias relatadas por Teresa, cuando afirma: "ssequedades ni trabajos interiores, sino con una memoria y ternura con nuestro Señor, que nunca querrían estar sino dándole alabanzas. Y cuando se descuidan, el mismo Señor las despierta... que se ve clarísimamente que procede de aquel impulso... de lo interior del alma... es como en la edificación del templo de Salomón, adonde no se había de oír ningún ruido" ${ }^{57}$. Pese a haber concentrado su comentario en el texto teresiano, la autora no se detiene

55 CI 97 SB 59: «Was Gott hier der Seele in einem Augenblick mitteilt, ist ein so großes Geheimnis, eine so hohe Gnade und erfüllt sie mit einer so außerordentlichen Wonne, daß ich es mit nichts anderem vergleichen kann als mit der himmlischen Glorie, die der Herr ihr für jenen Augenblick offenbaren will, und zwar auf eine so erhabene Weise wie durch keine andere Vision oder geistige Süßigkeit».

56 CI 97 SB 59s: «Der Strom, der sich der Seele mitteilt, überflutet von ihrem Innersten her auch ihre Kräfte. Es ist "deutlich wahrzunehmen, daß in unserem Innern... eine Sonne vorhanden ist, von der ein helles Licht ausströmt, das sich aus dem Innern der Seele auf ihre Vermögen ergießt. Die Seele weicht nicht von diesem Mittelpunkt und verliert nicht ihren Frieden ..."».

57 CI 98 SB 61: «Sie haben weder Trockenheit des Geistes noch innere Leiden, sondern ... sind ... von einer so zärtlichen Liebe" zum Herrn "erfüllt, daß sie ihn ohne Unterlaß, loben möchten. Werden sie aber hierin schläfrig, so weckt sie der Herr selbst wieder auf, sodaß ganz deutlich ist, diese Anregung gehe von dem Innernder Seele aus "sie kommt weder vom eigenen Denken noch vom Gedächtnis noch ist sie etwas, daß man denken könnte, die Seele habe ihrerseits etwas dazubeigetragen" "Alles, was der Herr zur Förderung und Belehrung der Seele hier tut, geschieht mit einer solchen Ruhe, daß es mich an den Bau des salomonischen Tempels erinnert, wo kein Lärm zu hören war». 
aquí, sino ofrece una explicación fenomenológica del mismo fenómeno, es decir del «reino del alma».

b. El camino por el alma recorrido en cuanto espíritu visto desde la fenomenología

Edith Stein admite, ciertamente, el valor eminente e incomparable de la explicación teresiana, pero no lo considera ajena a lo que la filosofía es capaz de comprender cuando comenta: "El reino del alma y el camino por ella recorrido desde el "muro de cerca" hasta el centro interior ha sido descrito, en lo posible, con las misma palabras de la Santa, porque difícilmente se podrían encontrar otras mejores. Será necesario ahora poner de relieve qué es lo que esta imagen del alma tiene en común con la que antes nosotros mismos hemos descrito ${ }^{58}$ (con criterios filosóficos), y qué es lo que tiene de diverso. Ante todo, es común la concepción del alma como un amplísimo reino, a cuya posesión debe llegar el propietario, porque precisamente es propio de la naturaleza humana (mejor dicho, de la naturaleza caida) el perderse en el mundo exterior. Pero en este perderse debemos distinguir la entrega objetiva, como lo hace el niño o el artista en un gesto que llega hasta el "olvido de sî" (61), pero que no excluye en un determinado momento un real retorno a la propia interioridad, y -por otro lado- el enredarse en las cosas del mundo, que hace brotar del deseo pecaminoso y que frena el "recogimiento" o puede convertirse en origen de una actividad errónea consigo mismo»"

58 Ser finito y ser eterno

59 CI 99: SB 61: «Das Reich der Seele und der Weg, den sie selbst von den Ringmauern bis zum Mittelpunkt zurücklegt, ist möglichst mit den eigenen Worten unserer heiligen Mutter dargestellt worden, weil man schwerlich bessere finden kann. Es soll jetzt nur noch hervorgehoben werden, was dieses Bild der Seele mit dem früher gezeichneten gemeinsam hat und was es davon unterscheidet. Gemeinsam ist vor allem die Auffassung der Seele als eines weitausgedehnten Reichesin dessen Besitz der Eigentümer erst gelangen muß, weil es dem Menschen von Natur aus (allerdings dürfen wir wohl sagen: von der gefallenen Natur aus) eigen ist, sich an die Außenwelt zu verlieren. Dabei ist zu scheiden zwischen der sachlichen Hingabe, etwa des Kindes oder des Künstlers, die bis zur Selbstvergessenheit geht, aber zur gegebenen Zeit eine ebenso sachliche Hinwendung ins eigene Innere nicht ausschließt, und der Verstrickung in die Dinge der Welt, die der sündhaften Begehrlichkeit entspringt und die Einkehr hemmt oder zur Quelle einer falschen Beschäftigung mit sich selbst werden kann». 
Pese a las semejanzas señaladas, la autora no niega las diferencias en el acercamiento de ambos intentos. Constata, pues, que «Esto nos lleva discretamente a la diferencia fundamental de las dos concepciones, que residen en la diversidad de los puntos de vista. Para la Santa es claro su objetivo: diseñar el castillo interior -casa de Dios- y hacer comprensible lo que ella misma ha experimentado: cómo el Señor mismo llama al alma de su extravío en el mundo exterior, cómo le atrae más y más a sí misma, hasta que finalmente Él pueda unirla aquí en el centro interior de ella misma. Queda absolutamente fuera del punto de mira de la Santa indagar si la estructura del alma (62) tenía además sentido, prescindiendo de este ser habitación de Dios, y si quizás habría otra "puerta", diversa de la oración. A las dos preguntas nosotros tenemos que responder, evidentemente, en sentido afirmativo" ${ }^{60}$.

Al continuar su comparación de dos posturas similares -comparación tan valiosa para la verificación de nuestra hipótesis, pues hace aplicable a todo ser humano lo que en Teresa a primera vista puede restringirse al "hombre religioso", las monjas-, Edith Stein efectivamente, se detiene en lo que sucede al alma humana, pero que «en cuanto espíritu e imagen del Espíritu de Dios, tiene la misión de aprender todas las cosas creadas conociéndolas y amándolas y así comprender la propia vocación y obrar en consecuencia. A los grados del mundo creado corresponden las moradas del alma: pero esto hay que entenderlo desde una profundidad diversa. Y si la morada más interior está reservada para el Señor de la Creación, también es cierto que solo a partir de la última profundidad del alma -punto céntrico del Creador-, puede recabarse una imagen realmente adecuada de la Creación: no será una imagen que abarque todo, como corresponde a (63) Dios, pero sí una imagen sin deformaciones. Queda así absolutamente a firme lo que la Santa expresó tan netamente: que entrar en sí mismo significa acercarse gradualmente a

60 CT 100 SM 62: «Das führt bereits auf den Hauptunterschied der beiden Darstellungen, der in der Verschiedenheit der leitenden Absichten begründet ist. Der Heiligen ist es rein darum zu tun, die Seelenburg, das Haus Gottes zu zeichnen und deutlich zu machen, was sie selbst erfahren hat: wie der Herr selbst die Seele aus ihrer Verlorenheit an die äußere Welt zurückruft, sie näher und näher an sich zieht, bis er sie schließlich in ihrem eigenen Mittelpunkt mit sich vereinen kann. Es lag ihr durchaus fern zu erwägen, ob dem Bau der Seele auch abgesehen von der Einwohnung Gottes noch ein Sinn zu komme und ob es vielleicht noch eine andere Pforte gebe als die des Gebets. Beide Fragen müssen wir anscheinend bejahend beantworten». 
Dios ${ }^{61}$. Aquí emerge un dato fundamental para la presente verificación de la hipótesis, la semejanza establecida entre el espíritu humano finito y el Espíritu Santo Infinito.

Tal semejanza, de hecho, nos hace avanzar en la dilucidación de las experiencias de interioridad, que constituyen el proceso formativo, ya que «Como espíritu y como imagen del Espíritu divino, el alma no solo tiene conocimiento del mundo externo sino de sí misma: es consciente de toda su vida espiritual (64) y es capaz de reflexionar sobre sí misma, incluso sin entrar por la puerta de la oración. Ciertamente hay que pensar con qué tipo de "yo" viene a encontrarse el alma y, consecuentemente, por cuál otra puerta puede entrar. Una posibilidad de entrada en su interior se la ofrece el trato con otros hombres. La experiencia natural nos da una imagen de ello y nos dice que también ellos tienen una imagen de nosotros. Y así llegamos, en cierto modo, a vernos a nosotros desde afuera. Es posible en ello constatar algunas apreciaciones correctas, pero rara vez penetramos más en lo hondo de nuestro interior; y a ese conocimiento van vinculadas muchas causas de error, que permanecen ocultas a nuestra mirada (65) hasta que Dios, con una neta sacudida interior -con una llamada interior- nos quita de los ojos la venda que a todo hombre le esconde en gran parte su propio mundo interior ${ }^{62}$.

61 CI 100 SB 62: «Die Menschenseele hat als Geist und Ebenbild des göttlichen Geistes die Aufgabe, die ganze geschaffene Welt erkennend und liebend aufzunehmen, ihren Beruf darin iu verstehen und entsprechend zu wirken. Dem Stufenbau der geschaffenen Welt entsprechen die Wohnungen der Seele: sie ist von einer verschiedenen Tiefe her zu erfassen. Und wenn die innerste Wohnung dem Herrn der Schöpfung vorbehalten ist, so gilt doch auch, daß nur von der letzten Tiefe der Seele aus, gleichsam vom Mittelpunkt des Schöpfers aus, ein wirklich entsprechendes Bild der Schöpfung zu gewinnen ist: immer noch kein allumfassendes, wie es Gott selbst eigenist, aber doch ein Bild ohne Verzerrungen. So bleibt durchaus bestehen, was die Heilige so klar gezeigt hat: daß das Eingehen eine schrittweise Annäherung an Gott bedeutet».

62 CI 100s SB 62s: «Als Geist und Bild des göttlichen Geistes hat die Seele nicht nur von der äußeren Welt, sondern auch von sich selbst Kenntnis: ihr ganzes geistiges Leben ist bewußt und ermöglicht ihr ein Zurückblicken auf sich selbst, auch ohne $\mathrm{da} ß$ sie durch die Pforte des Gebetes eingeht. ABerdings ist wohl zu bedenken, auf was für ein Selbst die Seele dann stößt, und das hängt damit zusammen, durch welche andere Pforte sie eingeht. Eine Möglichkeit des Zugangs ins Innere ergibt sich aus dem Verkehr mit anderen Menschen. Die natürliche Erfahrung gibt uns ein Bild von ihnen und führt uns darauf, daß auch sie ein Bild von uns haben. Und so kommen wir dazu, uns selbst gleichsam von außen zu betrachten. Es mag 
No cabe duda de que aquí emerge un peculiar aporte de alcance interdisciplinar que la autora precisa de la siguiente manera: «Finalmente pensemos en la investigación científica del "mundo interior", que se ha interesado por este tema del ser como de cualquier otro: resulta sorprendente qué es lo que ha quedado del reino del alma, desde que la "psicología" de nuestro tiempo ha comenzado a seguir su camino independientemente de toda consideración religiosa o teológica del alma: se llegó así, en el siglo XIX a una "psicología sin alma". Tanto la "esencia" del alma como sus "potencias" fueron descartadas como "conceptos mitológicos" y se quiso tomar en cuenta únicamente los "fenómenos psicológicos" (67). ¿Pero qué tipos de "fenómenos" eran esos?... Es como si (68) del "Castillo interior" se conservasen solo restos de muralla que apenas nos revelan la forma original, a la manera que un cuerpo sin alma ya no es un verdadero cuerpo" "63.

Pese a la visión poco alentadora de la ciencia psicológica emerge desde la comparación con el enfoque teresiano lo genuino de este enfoque y se clarifica mejor su contribución propia a nuestra indagación, pues constata Edith Stein: «Ante este campo de ruinas, uno se siente tentado a preguntar si, a fin de cuentas, la puerta de la oración no será el único ingreso al interior del alma. Realmente, la psicología naturalística del siglo XIX, en sus concepciones de fondo, hoy está ya superada. El redescubrimiento del espíritu y el interés por una auténtica "ciencia del espíritu” se cuentan ciertamente entre los más grandes cambios logrados en

manches Richtige dabei festgestellt werden, aber wir dringen dabei selten tiefer in uns ein; und es sind mit dieser Erkenntnis viele Fehlerquellen verbunden, die uns verborgen bleiben, solange uns Gott nicht durch eine wahrhafte innere Erschütterung-durch einen Rufins Innere- die Binde von den Augen nimmt, die jedem Men schen in besonderem Maße sein eigenes Innere verhüllt».

63 CI 101 SB 63: «Und denken wir schließlich an die wissenschaftliche Erforschung der inneren Welt, die sich diesem Seinsgebiet wie allen anderen zugewendet hat, so ist es ganz erstaunlich, was vom Reich der Seele übriggeblieben ist, seit die Psychologie in der Neuzeit begonnen hat, sich ganz unabhängig von a1len religiösen und theologischen Betrachtungen der Seele ihren Weg zu bahnen: das Ergebnis war im 19. Jahrhundert eine Psychologie ohne Seele. Sowohl das Wesen der Seele als ihre Kräfte wurden als mythologische Begriffe ausgeschaltet, und man wollte sich nur noch mit den psychologischen Phänomenen beschäftigen. Und was waren das für Phänomene ?.... Was heißt das anderes als daß man von der Seelenburg nur die llingmauern stehen ließ, und auch von ihnen nur Trümmer, die von der ursprünglichen Gestalt kaum noch etwas verrieten, da ja ein Leib ohne Seele kein wahrer Leib mehr ist». 
el campo científico durante las últimas décadas... Si volvemos la mirada a los pioneros de la nueva ciencia del espíritu y del alma (me refiero ante todo a Dilthey, Bretano, Husserly a sus escuelas) no tenemos ciertamente la impresión de que sus obras más importantes sean escritos religiosos y que sus autores hayan "entrado por la puerta de la oración" " ${ }^{64}$. Se plasma aquí una criticidad, que permite descubrir tanto las falencias como los aportes de los estudiosos en torno a Husserl.

\section{c. La ruptura con los fenómenos psíquicos, superada por el aporte místico}

Edith Stein se detiene, luego, a desglosar aspectos propios, aportados por los fenomenólogos, que evocamos en la medida en que nos ayudan a clarificar «las experiencias de la interiodad». Afirma la autora respecto a Husserl que «entonces hemos de pensar que no se trata de una mera yuxtaposición de estos hombres, sino de una profunda e íntima conexión» ${ }^{65}$.

64 CI 102 SB 64: «Angesichts dieses Trümmerfeldes wird man zu der Frage gedrängt, ob nicht am Ende doch die Pforte des Gebets der einzige Zugang zum Innern der Seele sei. Jene naturwissenschaftliche Psychologie des 19. Jahrhunderts ist zwar heute ihrer grundsätzlichen Auffassung nach überwunden. Die Wiederentdeckung des Geistes und das Bemühen um eine echte Geisteswissenschaft gehört sicher zu den größten Wandlungen, die sich in den letzten Jahrzehnten auf wisc senschaftliebem Gebiet vollzogen haben. Und nicht nur die Geistigkeit und Sinnerfülltheit des seelischen Lebens ist wieder zu. ihrem Recht gekommen, man hat auch seine Wirklichkeitsgrundlage wiedergefunden, wenn es auch immer noch Psychologen gibt- erstaunlicherweise sogar gläubige Katholiken- die es für unerlaubt halten, in wissenschaftlichen Zusammenhängen von der Seele zu sprechen. Wenn wir die Bahnbrecher der neuesten Geistes- und Seelenwissenschaft betrachten -ich denke vor allem an Dilthey, Brentano, H Husserl und ihre Schülerkreise- , so machen ihre entscheidenden Schriften gewiß nicht den Eindruck, als ob sie religiös bestinunt wären und als ob ihre Verfasser "durch die Pforte des Gebetes eingegangen" waren".

65 CI 103s SB 64: «Bedenken wir aber, daß Dilthey mit Fragen der protestantischen Theologie wohlvertraut war, wie z.B. seine Jugendgeschichte Hegels beweist; daß Brentano katholischer Priester war und auch nach seinem Bruch mit der Kirche, ja bis in seine letzten Lebenstage sich eifrig mit Glaubensund Gottesfragen beschäftigte; daß Husserl als Brentanos Schüler, ohne selbst die Theologie und Philosophie des Mittelalters zu studieren, eine gewisse lebendige Verbindung mit der großen Überlieferung der philosophia perennis hatte, daß er überdies persönlich im Kampf um sein philosophisches Lebenswerk stets vom Bewußtsein einer Sendung getragen war und daß im Kreise der Menschen, die ihm wissenschaftlich und menschlieh nahestanden, eine Starke Bewegung zur Kirche hin einsetzte, dann wird man doch nicht leicht ein bloßes Nebeneinander annehmen, sondern einen tiefen inneren Zusammenhang permuten dürfen». 
De hecho esto se aprecia en Pfänder «cuya concepción del alma concuerda ampliamente con la nuestra. Partiendo de una descripción de los movimientos del alma, Pfänder trata de comprender la vida del alma misma, descubriendo los impulsos fundamentales que la dominan. $\mathrm{Y}$ esos impulsos fundamentales intenta él reconducirlos a un impulso originario: a la tendencia del alma al autodesarrollo, tendencia basada en la esencia misma del alma» ${ }^{66}$.

Lamenta, por eso, Edith Stein una "ceguera», que "cabe pensar que la causa de esa ceguera y de la incapacidad de llegar a lo profundo del alma no reside simplemente en una obsesión en relación con algunos prejuicios metafísicos, sino en el inconsciente miedo a encontrarse con Dios. Por otra parte, ahí está el hecho de que nadie ha penetrado tanto en lo hondo del alma como los hombres que con ardiente corazón han abarcado el mundo, y que por la fuerte mano de Dios han sido liberados de todas las ataduras e introducidos dentro de sí en lo más íntimo de su interioridad ${ }^{67}$. Pero la autora admite que «también este es un punto en el que hemos constatado una concordancia entre nuestra exposición y el testimonio de la Santa: precisamente porque el alma es una realidad espiritual-personal, su ser más íntimo y específico, su esencia de la que brotan sus potencias y el despliegue de su vida, no son solo una desconocida $\mathrm{X}$ que nosotros admitamos para esclarecer los hechos espirituales que exprimentamos, sino algo que puede iluminarnos y dejar sentir aun cuando permanezca siempre misterioso» ${ }^{68}$.

66 CI 103 Ed 522: «Pfänder..., dessen Auffassung von der Seele weitgehend mit der unseren übereinstimmt. Von einer Beschreibung der seelischen regungen ausgehend, Bucht Pfänder das Verständis des seelischen Lebens durch Aufdeckung der es beherrschenden Grundtriebe zu erschliessen. Diese Grundtriebe führt er auf einen Urtrieb zurück: den Trieb der Seele nach Selbstauszeugung, der im Wesen der Seele begründet ist».

67 CI 104: Ed 523s: «unfassliche Blindheit: so möchte man meinen, dass nicht bloss Verranntheit in gewisse metaphysische Vorurteile, sondern eine unbewusst leitende Angst vor einer Begnung mit Gott die verblenedung herbeiführt und die Tiefen der Selle verhúllt haben mag. Auf der andern Seite steht die tatsache, dass niemand so in die Tiefen der Seele eingedrungen ist, wie die Menschen, die mit einem heissen Herzen die Welt umfasst hatten und dann durch die sarke Hand Gottess aus der Verstrickung gelöst und in das eigene Innere und Innerste hineingezogen wurden. Neben unserer heiligen Mutter Teresia steht hier in erster Linie, ihr im tiefsten wesnesverwandt und auch von ihr so empfunden, der heilige Augustinus».

68 CI 105 Ed 524: «Und das ist wiederum ein Punkt, in dem wir eine Übereinstimmung zwischen unserer Darstellung und den Zeugnissen der Heiligen festzustellen 
Finalmente, Edith Stein concluye que «El extraño camino que según la descripción de la Santa, recorre el alma en su interiorización -desde el muro hasta el centro más íntimo- puede, quizás, hacerse más comprensible mediante nuestra distinción (74) entre el alma y el Yo. El Yo aparece como un "punto" móvil dentro del "espacio" del alma; allá donde quiera que toma posición, allí se enciende la luz de la conciencia e ilumina un cierto entorno: tanto en el interior del alma, como en el mundo exterior objetivo hacia el cual el Yo está dirigido»" ${ }^{69}$.

\section{La Gracia supone la naturaleza y la perfecciona}

Si bien para Edith Stein es un hecho que "la Santa sabía que en sus conventos no eran raras las gracias místicas» ${ }^{70}$, es decir, que acontecen experiencias del misterio de Dios al interior del alma en cuanto espíritu finito, para la autora la índole extraordinaria de tales gracias no es de interés primordial como algo extraño y añadido al espíritu, sino supone una capacidad natural en dicho espíritu para recibir tales gracias, pero de manera que ellas perfeccionan la capacidad humana finita por desbordarla, desde y hacia lo infinito.

a. El ser «agraciada» en su capacidad natural

No cabe duda de que la naturaleza humana es comprendida por Edith Stein tanto en su estructura óntica profunda como práctica y muy dinámica, cuando interpreta a Teresa de Ávila, aunque hay una cierta priorización de la voluntad. Es precisamente dicha voluntad, que se transforma en receptáculo de la gracia, aunque sea incipiente todavía, como

haben: weil die Seele ein persönlich geistiges Gebilde ist, darum ist ihr Innerstes und Eigentlichstes, ihr Wesen, aus dem ihre Kräfte und das Wechselspiel ihres Lebensentspringen, nicht nur ein unbekanntes X, das wir zur Erklärung der erfahrbaren seelischen Tatsachen annehmen, sondern etwas was uns aufleuchten udn spürbar werden kann, wenn es auch immer geheimisvoll bleibt».

69 CI 105 Ed 524: «Der seltsame Gang, den die Seele bei ihrer Einkehr nach der Beschreibung der Heiligen zurücklegt -dass sie gleichsam sich selbst von den Ringmauern bis zum Innersten durchmisst-,wird vielleicht ein wenig verständlicher durch uniere Scheidung von Seele und Ich. Das ich erscheint als ein beweglicher "Punkt" im "Raum" der Seele; wo es jewiels seinen Standort nimmt, da leuchtet das Licht des Bewusstseins auf und erhellt einen gewissen Umkreis sowohl im Innern der Seele wie in der gegenständlichen Welt, der das Ich zugewendet ist».

70 CI 81 SB 40: «denn sie wußte, daß in ihren Klöstern mystische Begnadung nichts Seltenes». 
comenta la autora, diciendo: «si por su buena voluntad son frecuentemente agraciadas con consolaciones, estas consisten todavía en sentimientos totalmente naturales»" ${ }^{71}$. Más allá del pasivo "agraciada», es decir, se trata de algo recibido, emergen "consolaciones». Tales consolaciones, que, en general, se suelen comprender como de índole sobrenatural, aquí "consisten todavía en sentimientos totalmente naturales», es decir, el análisis se detiene a nivel de la naturaleza, ahondando su capacidad connatural para el regalo de Dios. Por lo cual la autora también concluye: "Lo expuesto hasta aquí indica el camino "natural" y "normal" del alma hacia sí misma y hacia Dios. Con ello no se quiere decir que hasta este punto no entre en juego lo sobrenatural ${ }^{72}$.

Es llamativo, luego, que tampoco a continuación el comentario steineano aborde directamente lo sobrenatural, sino nuevamente se detenga en la importancia de los "motivos naturales», cuando afirma: "Al contrario, cualquier impulso que mueva al hombre a entrar en sí mismo y lo encamine hacia Dios, debe ser visto como efecto de la gracia, aun cuando procede de hecho y motivos naturales» ${ }^{73}$. De hecho, aquí la distinción entre las consolaciones naturales y el efecto de gracia es precisada por Edith Stein a partir del «entrar en sí mismo y lo encamine hacia Dios", por lo cual resulta claro que el esfuerzo humano constructivista ya debe contar con la anticipación de la gracia.

En efecto, tanto Teresa como su comentarista se toman tiempo para abordar la naturaleza y su capacidad para acoger el don de la presencia de Dios en su interior, pues constata Edith Stein: "Hasta aquí el alma no ha experimentado nada de la presencia de Dios en su interior. Solo cuando suceda esto se podrá hablar de gracia "extraordinaria" o "mística". Esto comienza en las cuartas moradas» ${ }^{74}$. Esto sucede, sin duda,

71 CI 83: SB 43: «Und wenn sie für ihren guten Willen öfters durch Tröstungen belohnt werden, so sind das noch ganz natürliche Regungen».

72 CI 83 SB 43: «Das bisher Geschilderte zeigt uns den natürlichen und normalen Weg der Seele zu sich selbst und zu Gott. Damit soll nicht etwa gesagt sein, daß bis hierher nichts Übernatürliches mitspiele».

73 CI 83 SB 43: «Im Gegenteil, jede Anregung, die den Menschen zur Einkehr bei sich selbst bewegt und auf den Weg zu Gott bringt, ist als eine Wirkung der Gnade anzusehen, auch wenn dabei natürliche Ereignisse und Beweggründe als Werkzeuge benützt werden».

74 CI 83 SB 43: «Aber was die Seele bisher von Gott und seinem Verhältnis zu ihr weiß, das stammt aus dem Glauben, und den Glauben hat sie vom Hören. Gespürt 
en las cuartas moradas, cuando el alma ha experimentado «la presencia especial de Dios» en cuanto "agraciada», es decir, se trata de una presencia diferente a la presencia universal de Dios en todas las criaturas. Pero cuando el alma ha experimentado esta especial «presencia de Dios en su interior" se puede hablar de "gracia extraordinaria o mística».

De ahí que Edith Stein concluye: «La Santa llegó así, por el camino de la propia experiencia interior, a descubrir una verdad de fe que ignoraba hasta ese momento: "que Dios está en todas las cosas por presencia y potencia y esencia" -cf. relación 54-, y esto es algo bien diverso de la inhabitación divina por medio de la gracia» ${ }^{75}$. Cabe destacar el profundo significado que para Edith Stein adquiere la "propia experiencia» de Teresa, pues la Santa llegó así a «una verdad de fe», que además ignoraba hasta el momento. Es decir que Dios «está en todas las cosas por presencia, potencia y esencia», tríada muy escrutada desde siempre en la Antropología Teológica y diversa de la «inhabitación divina por medio de la gracia».

Edith Stein aquí no explica, por cierto, en qué consiste «la inhabitación divina en el alma» agraciada, como lo hace detenidamente en numerosos textos de su extensa obra, aun sin referirse a la enseñanza de la «Santa Madre». Pero sí queda claro que inhabitación como un «habitar en», designa un acto personal de parte de Dios y una libre colaboración de la voluntad humana, que lo acoge, que no se produce en un mismo nivel, sino por una anticipación de Dios, que significa aquella desemejanza en la semejanza, de la cual habla Letrán II y que solo puede darse como una verdadera paradoja, cuando se trata de la relación del espíritu finito con el infinito, relación que Edith Stein prefiere abordar a nivel de colaboración.

b. La paradoja de la colaboración del espíritu humano libre con el Espíritu Santo

Cuando Edith Stein recalca que es «Imposible querer entrar en esta "bodega" -Cf. Cant 2, 4- por el propio esfuerzo" y «"Su Majestad nos ha de

hat sie von der Gegenwart Gottes in ihrem Innern bisher nichts. Und erst wenn das geschieht, wird von außerordentlichem oder mystischem Gnadenleben gesprochen. Es beginnt in der vierten Wohnung».

75 CI 83 SB 47: «Die Heilige kam so auf dem Weg der inneren Erfahrung zu der Glaubenswahrheit, die ihr vorher unbekannt war: "daß Gott in allen Dingen ist durch seine Gegenwart, durch seine Macht und seine Wesenheit", und daß dieses etwas anderes ist als das Innewohnen durch die Gnade». 


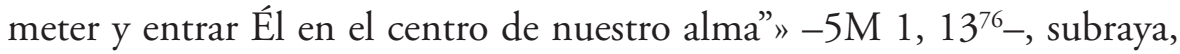
sin duda, la acción de Dios «en» «lo nuestro», es decir, destaca la condición de posibilidad. El acento es puesto en lo divino - "'Su Majestad nos ha de meter..."»-, que se puede temer por una verdadera autonomía de la libertad humana. Sin embargo, advierte Edith Stein de inmediato: «Pero el alma es capaz de realizar, con sus propias fuerzas, un trabajo preparativo" ${ }^{77}$, es decir, la naturaleza es capaz de actuar "con sus propias fuerzas", pero a modo de preparación. Emerge aquí una vez más toda la bondad natural de la criatura, que "la verdad de la fe» en un sentido católico nunca es negada ni por Teresa ni por Edith Stein. Pero sí de esta bondad fluye un modo de colaborar, singularmente importante para el proceso educativo.

En efecto, tal importancia de la colaboración es subrayada por la "graciosa imagen del gusano de seda», es decir, como a Teresa le faltan palabras y conceptos precisos para expresar el «misterioso colaborar»entre ambas libertades, recurre a un símbolo elocuente. Constata, pues, Edith Stein: «Esto será explicado mediante la graciosa imagen del gusano de seda: ..."cuando con el calor del Espíritu Santo se comienza a aprovechar del auxilio general que a todos nos da Dios, y cuando comienza aprovecharse de los remedios que dejó en su Iglesia”" $-5 \mathrm{M} 2$, $3^{78}$-. Resalta aquí la acción del Espíritu Santo, designada como «calor» aprovechada por el espíritu humano, junto con «los remedios» que Dios «dejó en su Iglesia». De tal modo que emerge la extraña paradoja, que destaca Edith Stein, siguiendo a Teresa, un tanto asombrada: «parecerá

76 CI 87 SB 47: "Durch eigene Anstrengung in diesen Weinkeller 23 zu gelangen, ist völlig unmöglich. "Die göttliche Majestät muß uns hineinbringen und selbst eintreten in den Mittelpunkt unserer Seele"».

77 CI 87 SB 47: «Aber die Seele ist doch imstande, aus eigener Kraft eine vorbereitende Arbeit dafür zu leisten».

78 CI 87 SB 47s: «Das wird erläutert durch das anmutige Bild des Seidenwürmleins: wie das kleine, starre Samenkörnchen durch die Wärme Leben gewinnt und anfängt, sich von den Blättern des Maulbeerbaums zu ernähren; wie es dadurch groß und stark wird und aus sich heraus die Seide spinnt und das Haus baut, worin das Würmchen stirbt, um dann als ein schöner, weißer Schmetterling daraus hervorzugehen so gewinnt die Seele Leben, "wenn sie, vom Heiligen Geist erwärmt, anfängt, die allgemeine Gnadenhilfe, die Gott uns allen gewährt, zu benutzen und die Mittel anzuwenden, die er in seiner Kirche hinterlassen hat"”. 
extraño que Dios mismo sea nuestra morada, y que nosotros seamos capaces de edificarla» ${ }^{79}$.

La capacidad paradójica que manifiesta el espíritu agraciado de "ser capaz de edificar nuestra morada» que es «Dios mismo", no será negada nunca, lo cual tiene consecuencias decisivas, pues Edith Stein evoca de modo acertado las palabras de Teresa, cuando afirma: «Porque una vez que ha gustado de tal paz -especialmente si esta gracia se le concede con frecuencia- todo lo que ve en la tierra le descontenta» ${ }^{80}$; más todavía, también es cierto que " Todo (28) le cansa, porque ha probado ya que el verdadero descanso no le pueden dar las criaturas" " $-5 \mathrm{M} 2,8^{81}$ - y que «es el mejor fruto de la unión» ${ }^{82}$. Pero cuando luego la autora agrega la observación: "Y esta (29) es también asequible a aquellos "a los que el Señor no da cosas tan sobrenaturales”" $-5 \mathrm{M} 3,3^{83}-$, se abre un camino que Edith Stein mismo recorrió desde su ser agnóstica hasta el bautismo y que GS 22 formula de manera tan lograda, cuando afirma que «El Espíritu Santo asocia a los no creyentes de modo solo conocido por Dios al Misterio Pascual».

Sin duda, aquí la paradoja de colaboración entre el espíritu humano y el Espíritu Santo alcanza su punto culminante, o mejor de mayor profundidad, siendo de valor incalculable para el avance del proceso formativo, como lo destaca luego también Edith Stein, cuando insiste «Lo más valioso de "la otra unión regalada" es "por proceder de esta que ahora digo y por no poder llegar a ella, si no es muy cierta la unión de estar resignada nuestra voluntad en la de Dios" ${ }^{84}$. Pero acota la autora, de modo cuidadoso, "Además, (31) "según es malo nuestro natural, si no es

79 CI 88 SB 48: «Es klingt seltsam, daß Gott selbst unsere Wohnung sei und daß doch wir imstande sein sollen, sie zu bauen».

80 CI 89: SB 49: «Denn nachdem sie eine solche Ruhe gekostet hat -besonders, wenn es öfters geschieht-, ist ihr alles auf Erden. Zuwider».

81 CI 89 SB 49: «Alles Irdische ist ihr zum überdruß, da sie erfahren hat, daß die Geschöpfe ihr die wahre Ruhe nicht geben können».

82 CI 89: SB 49: «ist die beste Frucht der Vereinigung».

83 CI 89 SB 49: "Und sie ist "auch von denen zu erlangen", "welchen der Herr keine übernatürlichen Gnaden mitteilt"».

84 CI 89 SB 49: «An jener "wonnevollen Vereinigung" ist das Wertvollste, "daß sie hervorgeht aus derjenigen, von welcher ich jetzt rede, und wir können nicht zu ihr gelangen, wenn nicht die Vereinigung, die in der völligen Hingabe unseres Willens in den göttlichen besteht, eine ganz wahre ist"”. 
naciendo de raíz del amor de Dios, no llegaremos a tener con perfección el del prójimo"» $-5 \mathrm{M} 4,9^{85}$-. Edith Stein no explica aquí el origen de la fórmula " "es malo nuestro natural"», como lo hace en otro momento, es decir, la naturaleza humana no es mala en cuanto "creada", sino más bien por ser "constituida" mala a causa del pecado original originante de Adán, un misterio de iniquidad impenetrable con la mera razón y sin embargo salvífico.

De ahí que Edith Stein concluye, acertadamente: «Así, existen claramente dos caminos para la unión con Dios, y a la vez para la perfección del amor: una vida fatigosa con el propio esfuerzo, cierto no sin la ayuda de la gracia; y el ser llevados hacia lo alto, con gran ahorro de trabajo personal, pero en cuya preparación y realización se le exige muchísimo a la voluntad ${ }^{86}$, es decir, para Edith Stein es indispensable la colaboración de la voluntad humana, pero ella es perfeccionada por medio del regalo de las «gracias místicas».

c. El perfeccionamiento de lo natural por medio de las gracias místicas

No cabe duda de que la colaboración paradójica entre voluntad humana y acción anticipadora de Dios desemboca en el significativo regalo de «las gracias místicas», preparado progresivamente hasta su grado más alto, lo cual Edith Stein describe así: "para las almas que Dios conduce por el camino de las gracias místicas, la oración de unión es solo preparación para un grado más alto: el desposorio espiritual, que tiene lugar en las sextas moradas ${ }^{87}$. No se trata de experiencias del todo expresables, pues advierte la autora comentando a Teresa: «A pesar de que, después, no se sepa decir nada de estas gracias, "de tal manera queda impresa en

85 CI 90 SB 50: «überdies würden wir "bei der Verderbnis unserer Natur ... die Liebe zum Nächsten nie vollkommen üben, wenn sie nicht aus der Liebe Gottes, als aus ihrer Wurzel hervor sproßt"”.

86 CI 90 SB 50: «So gibt es offenbar zwei Wege zur Vereinigung mit Gott und damit zur Vollkommenheit der Liebe: ein mühsames Emporklimmen durch eigene Anstrengung, freilich mit Gottes Gnadenhilfe, und ein Emporgetragenwerden, das viel eigene Arbeit erspart, dessen Vorbereitung und Auswirkung aber doch an den Willen hohe Anforderung stellt».

87 CI 90 SB 50: «Im übrigen ist für die Seelen, die der Herr auf dem mystischen Gnadenweg führt, das Gebet der Vereinigung nur eine Vorbereitung für eine noch höhere Stufe: die geistige Verlobung, die in der sechsten Wohnung stattfindet». 
la memoria (43) que nunca jamás se olvidan”" -(escala de Jacob) ${ }^{88}$. Por eso, concluye Edith Stein, «Es esta su preparación inmediata para llegar al más alto grado de la vida de gracia que puede alcanzarse en la tierra» ${ }^{89}$.

Los entendidos saben que aquí aflora una realidad que Ex 33, 20 -texto frecuentemente citado- liga a la muerte, «nadie puede ver a Dios y seguir viviendo", mientras Jacob, a cuyo contexto apunta la imagen de la escalera insiste en que ha visto a Dios y sigue viviendo. Para Edith Stein, indudablemente «Es un secreto tan grande y una merced tan subida lo que comunica Dios allí al alma en un instante y el grandísimo deleite que siente el alma, que no sé a qué comparar, sino a que quiere el Señor manifestarle por aquel momento la gloria que hay en el cielo, por más subida manera que por ninguna visión ni gusto espiritual $\aleph^{90}$. Pero la autora admite, que «Esto es lo que se deja quizás entender, de lo que la Santa ve como fin de todo ese camino de gracia: un fin que no consiste solo en la "divinización de las almas", sino que todas las gracias deben servir "para fortalecer nuestra flaqueza... para imitar a Cristo en el mucho padecer" " ${ }^{11}$.

La experiencia descrita, sin duda, es el norte de todo el proceso formativo, como subraya Edith Stein: «Hacia ese punto se sentirá llamado siempre (nuevamente se trata de un punto que hemos tenido que llevar

88 CI 93 SB 55: «Trotzdem man von diesen Gnaden nachher nichts zu sagen weiß, "bleiben sie doch dem Innersten der Seele so tief eingeschrieben, daß man ihrer nie mehr vergißt" und "gewisse Wahrheiten von der. Größe Gottes einer solchen Seele sich so tief einprägen, daß sie, selbst wenn sie den Glauben noch nicht hätte, der ihr sagt, wer Gott ist und daß sie verpflichtet sei, ihn als Gott zu glauben, von diesem Augenblick an ihn als Gott anbeten würde, wie Jakob getan, als er die Leiter geschaut"”.

89 CI 97 SB 58: «Das ist ihre letzte V orbereitung für die Erhebung auf die höchste Stufe des Gnadenlebens, die auf Erden erreichbar ist».

90 CI 97 SB 59: «Was Gott hier der Seele in einem Augenblick mitteilt, ist ein so großes Geheimnis, eine so hohe Gnade und erfüllt sie mit einer so außerordentlichen Wonne, daß ich es mit nichts anderem vergleichen kann als mit der himmlischen Glorie, die der Herr ihr für jenen Augenblick offenbaren will, und zwar auf eine so erhabene Weise wie durch keine andere Vision oder geistige Süßigkeit».

91 CI 99 SB 61: «Die Verzückungen hören auf dieser Stufe fast ganz auf. Das läßt sich vielleicht aus dem verstehen, was die Heilige als den Zweck der ganzen Gnadenführung ansieht. Das ist nicht etwa nur die "Ergötzung der Seelen". Vielmehr sollen alle Gnaden "zur Stärkung unserer Schwachheit dienen, damit wir dem Herrn durch Ertragung vieler Leiden nachfolgen” 93 und rastlos für das Reich Gottes wirken. "Dahin zielt das innerliche Gebet und dazu dient auch die geistige Vermählung, daß unaufhörlich Werke, lauter Werke daraus hervorgehen ...”". 
más allá de cuanto nos dice al respecto El Castillo Interior), no solo es convocado ahí a las más altas gracias místicas del desposorio espiritual con Dios, sino que desde aquí puede tomar las decisiones últimas a que es llamado el hombre como persona libre» ${ }^{92}$. Resalta el alcance que se desprende de esta constatación: la acción de la gracia desbordante es el fin de todo el proceso formativo, pero no se realiza ni mínimamente sin el sí de la «persona libre».

Edith Stein concluye así de modo significativo: «Ella (la voluntad de Dios) es la medida de nuestra santidad, y a la vez la condición para la unión mística que no está en nuestro poder, sino que es libre regalo de Dios. Pero de aquí resulta también (76) la posibilidad de vivir desde el centro del alma y de realizarse a sí mismo y la propia vida, sin ser agraciados con gracias místicas» ${ }^{93}$.

\section{LOS DESEOS MÁS ÍNTIMOS DEL SER HUMANO Y SU CUMPLIMIENTO}

Si intentamos preguntar ahora por los deseos más íntimos del ser humano desde los cuales arrancó el camino recorrido, es que pretendemos desentrañar las motivaciones más profundas que impulsaron el proceso, a la vez que orientamos nuestra mirada hacia la meta del perfeccionamiento anhelado a través del proceso formativo. De hecho, Edith Stein se plantea la pregunta "¿qué cosa puede mover a ese hombre totalmente "exteriorizado", a entrar por la puerta de la oración, cuando aún no percibe tales llamadas? La Santa no nos lo explica». La autora continúa, "Sospecho que ella lo encuentra obvio para el hombre que, por su educación religiosa, está ya habituado a orar en ciertos momentos, y por otro lado está suficientemente instruido en las verdades de la fe

92 CI 105 Sb 67: «Hierhin wird es immer wieder gerufen und zwar - das ist wieder ein Punkt dem wir über das hinausgehen mußten, was uns die Seelenburg bezeugtnicht nur zur höchsten mystischen Begnadung, der geistlichen Vermählung mit Gott, sondern um von hier aus die letzten Entscheidungen zu treffen, zu denen der Mensch als freie Person aufgerufen wird».

93 CI 106 SB 68: «Sie ist das Maß unserer Heiligkeit. Sie ist zugleich die Bedingung der mystischen Vereinigung, die nicht in unserer Macht steht, sondern freies Geschenk Gottes ist. Darum ergibt sich aber auch die Möglichkeit, vom Mittelpunkt der Seele aus zu leben, sich selbst 41 nd sein Leben zu gestalten, ohne mystisch begnadet zu sein». 
para pensar en Dios cuando reza» ${ }^{94}$. La respuesta steineana, sin duda, es convincente, pero además se completa por la convicción de la autora de que junto con la entrada por la puerta de la oración la fenomenología dispone de un acceso, igualmente, válido, pero aplicable a todo hombre, ella lo detalla en la última parte de su estudio cuando analiza los detalles de la estructura del espíritu humano. En efecto, son principalmente tres deseos que aglutinan los demás y que se perfilan mejor en cuanto a su relevancia actual para el proceso educativo.

a. El deseo de glorificar a Dios en esta vida y después de la muerte

Como deseo primordial emerge una verdad que además constituye el fin último del ser humano: criatura puesta por Dios en el mundo, es decir, creada para "glorificar» y «alabar a Dios», en cuanto origen fundante de todo cuanto existe. Esto suena idílico si no recordamos las dificultades enfrentadas a lo largo del proceso formativo y las desavenencias todavía existentes, ya que Edith Stein insiste en que «Lo contrario serviría solo para procurar sequedad al alma, que se dañaría a sí misma con sus propios forcejeos, sumergiría en la agitación a la imaginación y entendimiento, descuidando "lo más sustancial y agradable a Dios", es decir, "que nos acordemos de su honra y gloria y nos olvidemos de nosotros mismos y de nuestro provecho y regalo y gusto. Pues, ¿cómo está olvidado de sí el que con mucho gusto y cuidado está, que no se osa bullir, ni aun deja a su entendimiento y deseos que se bullan a desear la mayor gloria de Dios, ni que se huelguen de la que tiene?"» -4 M 3, $6^{95}$.

94 CI 83: SB 42: «Ich vermute, daß sie wie selbstverständlich mit Menschen rechnet, die durch ihre fromme Erziehung daran gewöhnt sind, zu gewissen Zeiten zu beten, und genügend in den Glaubenswahrheiten unterrichtet, um in ihrem Sinn an Gott zu denken, während sie beten)».

95 CI 85s SB 45: «Sonst würde die Seele nur in Trockenheit geraten, sie würde sich durch ihre peinliche Anstrengung selbst schaden, die Einbildungskraft und den Verstand erst recht in Aufregung bringen und das "Wesentlichste und Gottgefälligste" außer acht lassen, "daß wir an seine Ehre und Verherrlichung denken und uns selbst, unseren Vorteil, unseren Trost und unser Vergnügen vergessen. Wie kann aber einer sich selbst vergessen, der so sorglich auf sich acht hat, daß er sich nicht zu bewegen getraut, ja nicht einmal seinem Verstand und seinen frommen Begierden sich zu rühren gestattet, um sich zu freuen über die Herrlichkeit Gottes und Verlangen zu tragen nach immer größerer Verherrlichung der göttlichen Majestät?”». 
Pese a todo, advierte la autora, "Se despierta en ella un irresistible deseo de alabar a Dios (27) y de sufrir por Él. Tiene ansias de penitencia y soledad. Le brotan "deseos grandísimos... de que todos conociesen a Dios; y de aquí le viene una pena grande de ver que es ofendido"» $-5 \mathrm{M} \mathrm{2}, 7^{96}-$. Cabe fijarse en cómo el «deseo irresistible» de alabar se une aquí a "ansias de penitencia y soledad», pero más todavía a los «"deseos grandísimos" de que "todos conociesen a Dios"», junto con «"una pena grande de ver que es ofendido"”, es decir, aquí emerge una singular complejidad de la realidad del deseo, que tiene tanto sus expresiones jubilosas como penosas.

Luego Edith Stein resume: "“Todo se le hace poco cuanto puede hacer por Dios, según son sus deseos...; el atamiento con deudos, o amigos o hacienda (que ni le bastaban actos ni determinaciones ni quererse apartar...) ya se ve de manera que le pesa estar obligada..." "»7 , es decir, el «más» que se reveló anteriormente de parte de lo que Dios regala, ahora pasa a ser la dinámica propia del ser humano. Lo cual involucra el deseo por morir.

En efecto, «esto es, el deseo de partir de esta vida, por nadie sentido tan intensamente como por el Hijo de Dios. Y a la vez, el amor a las almas, y el deseo de salvarlas, que a Él le ocasionaron sufrimientos tan insoportables que en su comparación la muerte y las penas que la precedieron le parecieron cosa de nada ${ }^{98}$. Resulta relevante el ejemplo del «Hijo de Dios» en cuanto quien como nadie ha «sentido tan intensamente» «el deseo de partir de la vida», pero "por amor a las almas», es decir, para «salvarlas». Edith

96 CI 88 SB 49: «Es erwacht in ihr ein unwiderstehliches Verlangen, Gott zu preisen und für ihn zu leiden. Sie sehnt sich nach Bußübungen und Einsamkeit. "Dazu hegt sie den sehnlichsten Wunsch, daß alle Menschen Gott erkennen möchten, und sieht sie, daß er beleidigt wird, so empfindet sie großen Schmerz"».

97 CI 89 SB 49: «Alles, was die Seele für Gott tun kann, ist ihr im Verhältnis zu ihrem Verlangen zu wenig... Ihre Anhänglichkeit an Verwandte, Freunde und zeitliche Güter ist geschwunden, und .Weder. fromme Anmutungen noch gute Vorsätze noch das Verlangen reichten vorher hin, sich davon zu trennen ... Alles Irdische ist ihr zum überdruß, da sie erfahren hat, daß die Geschöpfe ihr die wahre Ruhe nicht geben können».

98 OI 89 SB 49: «Das ist das V erlangen, dieses Leben zu verlassen, das wohl niemand sehnlicher empfunden hat als der Gottessohn. Und daneben die Liebe zu den Seelen und das Verlangen, sie zu retten, die ihm so entsetzliches Leiden verursachten, daß ihm der Tod und die Pein, die ihm vorausgehen sollten, im Vergleich dazu wie nichts erscheinen». 
Stein acentúa este ejemplo en todas sus dimensiones deseadas y así llevados como nadie a su cumplimiento. Esto significa que el «más» anhelado por el alma progresada, tiene un fundamento seguro y siempre incitante hacia una superación mayor. A esta profundidad existencial posibilitada por el ejemplo, que es ayuda concreta, se encuentra luego vinculado otro deseo, el de hacer la voluntad de Dios.

b. El anhelo de hacer la voluntad de Dios y trabajar por la salvación de las almas

Para comprender la profundidad existencial del deseo de «hacer la voluntad de Dios y trabajar por la salvación de las almas», cabe fijarse en que Edith Stein lo concibe no solo como el deseo «mejor», sino también en cuanto "fruto de la unión", es decir, conseguido trabajosamente a lo largo del escabroso proceso formativo, pero siendo regalo exclusivo de Dios, ya que insiste la autora en que «Este deseo de hacer la voluntad de Dios y trabajar por la salvación de las almas, incluso por la propia, es el mejor fruto de la unión»"99.

Lo señalado recién, que nos ubica en la sexta morada, tampoco significa reposo ni ausencia de sufrimientos, lo cual subraya Edith Stein cuando insiste: «Pero tampoco la sexta morada es lugar de reposo para el alma. Su anhelo mira a la unión estable y duradera que se le concederá solo en la morada séptima, y todavía el alma es probada con los más intensos sufrimientos, externos e internos» ${ }^{100}$.

Pero resulta relevante que "A veces el alma es "tocada" en forma tal por una palabra de Dios que cae en éxtasis: "parece que Su Majestad desde lo interior del alma hace crecer la centella que dijimos ya, movido de piedad de haberla visto padecer tanto tiempo por su deseo, que abrasada toda ella como un ave fénix queda renovada...” ${ }^{101}$. De ahí que Edith

99 OI 89 SB 49: «Dieses V erlangen, um Gottes willen für das Heil der Seelen (auch der eigenen) zu wirken, ist die beste Frucht der Vereinigung».

100 OI 90 SB 51: «Aber auch die sechste Wohnung ist noch nicht der Ort der Ruhe für die Seele. Ihre Sehnsucht verlangt nach der dauernden Vereinigung, die ihr erst in der siebenten Wohnung gewährt werden soll, und sie wird noch durch die härtesten äußeren und inneren Leiden erprobt».

101 OI 93 SB 54: «Manchmal wird die Seele von einem Gotteswort so betroffen, daß sie in Verzückung gerät: "Es scheint, als ob der Herr, von Mitleid wegen der Leiden, die er sie so lange Zeit in ihrem Verlangen nach ihm erleiden sah, gerührt, 
Stein subraya "Como efecto le nace un vivo anhelo de morir y el deseo de guardarse de la más pequeña imperfección» ${ }^{102}$.

c. El deseo de sufrir

Cuando la autora se detiene en comentar la sexta morada, destaca un hecho inesperado, diciendo: "Todas las gracias que se reciben en la sexta morada, sirven solo para avivar en el alma el deseo de sufrir, "porque como va conociendo más y más las grandezas de su Dios y se ve estar tan ausente y apartada de gozarle, crece mucho más el deseo; porque también crece el amar mientras más se le descubre lo que merece ser amado este gran Dios y Señor" " ${ }^{103}$. Este primer efecto de la entrada en la sexta morada solo es comprensible si se recuerda también aquí el ejemplo del Hijo de Dios.

Edith Stein indica, luego, «El segundo efecto es "un deseo de padecer grande, mas no de manera que la inquiete como solía; porque es un tanto extremo el deseo que queda en estas almas de que rehaga la voluntad de Dios en ellas, que todo lo que Su Majestad hace tienen por bueno". Y si antes deseaba la muerte, "ahora es tan grande el deseo que tienen de servirle y que por ellas sea alabado, y de aprovechar algún alma si pudiesen (58), que no solo no desean morirse, mas vivir muy muchos años padeciendo grandísimos trabajos, por si pudiesen que fuese el Señor alabado por ellos" ${ }^{104}$. No se trata de una actitud masoquista, sino de la más perfecta asimilación por amor a Cristo el Señor, para que Él sea alabado.

aus ihrem Innern den schon besprochenen Funken auflodern ließe. Dadurch ganz verzehrt, geht sie dann, gleich dem Vogel Phönix, verjüngt aus der Glut hervor"».

102 CI 95 SB 56: «Als weitere Wirkung bleibt eine große Sehnsucht zu sterben und das Verlangen, sich vor der geringsten Unvollkommenheit zu hüten».

103 CI 95 CI 95 Sb 57: «Alle Gnaden, die in der sechsten Wohnung empfangen werden, dienen nur daZu, ihren Sehnsuchtsschmerz zu steigern, "weil mit der mmer mehr zunehmenden Erkenntnis der Herrlichkeiten ihres Gottes, vori: dessen Genuß sie sich noch so getrennt und fern sieht, ihr Verlangen nach ihm immer viel heftiger wird; denn auch ihre Liebe wächst in dem Grade, in welchem ihr dieser große Gott und Herr zu erkennen gibt, wie sehr er geliebt zu werden verdient"».

${ }^{104}$ CI 98 SB 60: «... “ist großes Verlangen zuleiden”, “aber ohne” "daß es diese Seelen beunruhigte, wie dies sonst cier Fall war. Denn sie verlangen so sehr, daß in allem Gottes Wille in ihnen geschehe, daß ihnen alles recht ist, was immer Seine Maj. estät tut" 87. Und wenn sie sich früher nach dem Tode sehnten, so ist jetzt ihr Verlangen, Gott "zu dienen und zu seinem Lobe zur Förderung irgendeiner Seele, Wenn es möglich wäre, beizutragen, so groß, daß sie, weit entfernt von dem Ver- 
La autora concluye, finalmente, destacando la trasformación decisiva de los deseos cuando comenta en las alma perfectas que "Ya no tienen deseos "de regalos ni de gustos" espirituales. Viven en "un desasimiento grande en todo y deseo de estar siempre a solas u ocupadas en cosa que sea provecho de algún alma” ${ }^{105}$.

\section{A MODO DE CONCLUSIÓN}

Cabe apreciar cómo en la obra Die Seelenburg de Edith Stein, la hipótesis «Educar para la gracia desbordante conduce a la plena autorrealización de los participantes del proceso formativo, a partir de los deseos más intimos de sus corazones", no solo se verifica paso a paso, sino que se traduce en resultados concretos, obtenidos en dos Cursos de Antropología Teológica 2011, especialmente, en las respuestas concretas a la pregunta: ¿En qué medida la gracia desbordante responde a los deseos más íntimos del ser humano en el mundo?, resultados que a su vez se abren a pistas prácticas prometedoras, que solo pueden ser trabajadas por una investigación nueva.

Los deseos más íntimos constatados y explicitados, detalladamente, en los trabajos de los alumnos desde el contexto chileno latinoamericano, emergen a partir de la estructura fundamental de un ser humano en el mundo, abierto a la trascendencia, pero obstaculizado, de múltiples maneras, en la consecución de su fin último, la felicidad. Para poder concretar estos deseos y superar los obstáculos que se les presentan en su autorrealización, Edith Stein, sin duda, nos ofrece una ayuda valiosísima, al interpretar antropológica teológicamente la obra El Castillo Interior de Teresa de Ávila. Como su gran Maestra, la fenomenóloga comprende al ser humano fundamentalmente como un ser que desea "amar y ser amado», lo cual implica un enorme esfuerzo de parte del educando, pero, en definitiva, es regalo, de Aquel quien se autodona en cuanto Gracia, siempre desbordante y mediada por el educador. Los aportes elaborados por los alumnos de ambos Cursos de Antropología

langen zu sterben, vielmehr noch recht lange unter den größten Leiden zu leben wünschen, damit, wenn es möglich wäre, der Herr durch sie gelobt werde ... "”.

105 CI 98 SB 60: "Sie haben "auch kein Verlangen mehr nach geistlichen Wonnen und Süßigkeiten", "leben in einer großen Losschälung von allem Geschaffenen und wünschen, immer allein zu sein oder zum Nutzen irgendeiner Seele sich zu beschäftigenz"». 
Teológica ejemplifican esta verdad con ahínco, pero la plasman en detalles llamativos, que aterrizan los grandes deseos detectados por Edith Stein, de modo "constructivista", es decir, el deseo de autorrealizarse a partir de otro - "glorificar a Dios»-, de aprender a «morir» y lograr un sentido positivo del sufrimiento, connatural a la situación del hombre en el mundo.

1. El deseo de autorrealizarse a partir de otro, es decir, «glorificar a Dios» y hacer Su voluntad, sin duda, es el deseo abordado por la Antropología Teológica en su especificidad. Los ejercicios prácticos realizados a lo largo de los dos Cursos lograron, de hecho, despertar una aguda toma de conciencia de la gratuidad que trasciende y completa el método constructivista y explica los momentos "críticos» en la asimilación de una materia que conlleva el peligro de la abstracción, siendo a la vez su contenido el más concreto de todas las materias teológicas, ya que compromete al educando con la interpretación personal de su propia existencia y la de los demás más allá de los conocimientos teóricos impartidos. El «glorificar a Dios», por su parte, canaliza fuerzas y capacidades inauditas en el educando, siendo una respuesta a la generosidad innata del joven, que se articula, de modo más visible, en la medida en que él avanza en la «construcción» de su formación teológica práctica.

2. El deseo de aprender a «morir»: pese a la vitalidad que marca la existencia del joven educando, su situación concreta en el mundo es precaria y siempre expuesta al fracaso y la muerte, es decir, a un fin definitivo e innegociable. Si esto no es tomado en serio o hasta es ignorado, todo el proyecto práctico formativo, en definitiva, fracasa. De ahí el aporte importante que Edith Stein articula como un aprendizaje de morir para «salvar a otros». Los alumnos atestiguan esta verdad, cuando destacan el deseo de superar situaciones negativas hasta absurdas, producidas por el Pecado Original como explica la Antropología Teológica, por medio de la Gracia, que sobreabunda allí donde el pecado abunda -Rm 5, 20-. El método constructivista aplicado ha revelado la fuerza de la «sanación» que más que rehabilitación es «renovación del hombre interior». De tal modo, la muerte no es una maldición temida, sino plenificación del amor siempre mayor.

3. El deseo de encontrar un sentido positivo en el sufrimiento, connatural a la situación del hombre en el mundo y propio de una formación 
teológica práctica, por esencia «autocrítica», resalta, permanentemente, a través del proceso de formación descrito y vivido por Edith Stein. De hecho, la relevancia del «sufrimiento» para el crecimiento humano es innegable, tan solo que las respuestas que el formando con frecuencia recibe son insuficientes, ya que las posibildades de apaciguar, de modo natural, el dolor, son pasajeras e incrementan la sensación de frustración, mientras un «padecer» junto con Aquel que «sufrió por nosotros», imitándolo, no solo da fuerza para "aguantar», sino también permite descubrir que las heridas son "gloriosas" en cuanto transformadas por un Amor siempre mayor, la Gracia desbordante. 
Resumen: Si bien el estudio de Edith Stein Die Seelenburg es un comentario a Las Moradas de Teresa de Ávila y como tal evoca muchos aspectos tratados en profundidad desde una perspectiva lingüística y teológica espiritual, el aporte propio de la santa filósofa resalta en aquellos acentos que ella, más allá de las referencias a la obra teresiana, ofrece a partir de un enfoque fenomenológico. Se analiza e interpreta estos acentos desde una perspectiva teológica sistemática para verificar la relevancia teológica de estos acentos para el proceso formativo de educar al ser humano hoy. Los pasos metodológicos concretos, analíticos y sintéticos a la vez, del método aplicado a Die Seelenburg de Edith Stein se configuran a modo de una «lectura orgánica del texto». Se insiste en los fundamentos teológicos que emergen del texto steineano y que podrá constatarse en cuanto propio de su forma mentís.

Palabras clave: Gracia desbordante, deseos, corazón humano, teología práctica.

Abstract: While Edith Stein's study Die Seelenburg is a commentary on Las Moradas by Teresa of Avila and as such evokes many aspects covered in depth from a theological, spiritual and linguistic perspective, the contribution of the holy philosopher highlights those accents that she, beyond references to the work of Teresa of Avila, offers from a phenomenological approach. These accents are analyzed and interpreted from a systematic theological perspective to verify their theological relevance for the formative process of educating the human being today. The specific methodological steps, at once analytical and synthetic, of the method applied to Edith Stein's Die Seelenburg are configured through an "organic reading of the text." There is emphasis on the theological foundations that emerge from Stein's text and which may be established as inherent to her forma mentis.

Keywords: Overflowing grace, desires, human heart, practical theology 